\title{
Functionalization of magnetic chitosan microparticles for high-performance removal of chromate from aqueous solutions and tannery effluent
}

\author{
Mohammed F. Hamza ${ }^{\text {a,b,c }}$, Doaa M. Hamad ${ }^{\text {d }}$, Nora A. Hamad ${ }^{\text {d }}$, Adel A.-H. Abdel-Rahman ${ }^{\text {d }}$ \\ Amr Fouda $^{\mathrm{e}}$, Yuezhou Wei ${ }^{\mathrm{a}, \mathrm{b}, *}$, Eric Guibal ${ }^{\mathrm{f}, *}$, Abd-Allah S. El-Etrawy ${ }^{\mathrm{g}}$ \\ ${ }^{a}$ School of Nuclear Science and Technology, University of South China, Heng Yang, 421001, China \\ ${ }^{\mathrm{b}}$ School of Resources, Environment and Materials, Guangxi University, Nanning 530004, China \\ ${ }^{\mathrm{c}}$ Nuclear Materials Authority, POB 530, El-Maadi, Cairo, Egypt \\ ${ }^{\mathrm{d}}$ Faculty of Science, Menoufia University, Shebine El-Koam, Egypt \\ ${ }^{\mathrm{e}}$ Botany and Microbiology Department, Faculty of Science, Al-Azhar University, Nasr City, Cairo 11884, Egypt \\ ${ }^{\mathrm{f}}$ Polymers Composites and Hybrids (PCH), IMT Mines Ales, Alès, France \\ ${ }^{g}$ Department of Chemistry, Basic Science Center and Pharmaceutical Organic Chemistry College of Pharmaceutical Science \& Drug Manufacturing, Misr University for \\ Science and Technology (MUST), $6^{\text {th }}$ of the October City 77, Egypt
}

\section{A B S T R A C T}

Textile and tannery industries are highly contaminating with discharge of high $\mathrm{Cr}$ concentrations. Developing bio-based sorbents with strong affinity for chromate, fast kinetics, and high recyclability is strategic for better reuse of industrial wastewater. Magnetic chitosan micro-particles (MC, for enhancing mass transfer) may constitute a solution for chromate removal from acidic solutions. The functionalization of this support with aminothiazole groups (ATA@MC) or imidazole carboxamide (AIC@MC) significantly improves chromate removal, with sorption capacities close to $6 \mathrm{mmol} \mathrm{Cr} \mathrm{g}^{-1}$, at pH 2. The Langmuir and the Sips equations finely fit sorption isotherms, while the pseudo-first order rate equation fits well uptake kinetics (equilibrium within 60 $\min$ ). Sorption and desorption properties are remarkably stable: sorption efficiency decreases by less than $6 \%$ at the fifth cycle (while the desorption efficiency maintains above 99\%). The sorbents are highly selective for chromate removal from acidic tannery wastewater (against base metals). FTIR and XPS analyses are used for characterizing the materials and for identifying the binding mechanisms (including chromate reduction into $\mathrm{Cr}$ (III)). The sorbents are both showing promising performances for $\mathrm{Cr}(\mathrm{VI})$ removal in acidic solutions, including in very complex solutions such as tannery wastewater. AIC@MC is more selective for $\mathrm{Cr}(\mathrm{VI})$ removal, while ATA@MC has a broader reactivity for a wider family of metal ions. The antimicrobial properties of the functionalized sorbents are characterized by the determination of the zone of inhibition (ZOI) against Staphylococcus aureus, Bacillus subtilis, Pseudomonas aeruginosa, Escherichia coli and Candida albicans: the inhibition is slightly improved compared with magnetite chitosan microparticles. More generally, the Gram bacteria are slightly more sensitive to the functionalized sorbents than $\mathrm{Gram}^{+}$bacteria and Candida fungus.

\section{Keywords:}

Functionalization of magnetic chitosan

nanoparticles for improving chromate removal

Sorption isotherms and uptake kinetics

Metal desorption and sorbent recycling

Characterization of sorption mechanisms by

FTIR and XPS analyses

Antimicrobial activity of functionalized

materials

Application to tannery wastewater

\section{Introduction}

The protection of water resources is becoming a critical challenge for industrial development. The increasing pressure on water demand, the requirements of the population for developing processes more respectful of the environment have driven world and regional organizations to elaborate drastic regulations for the discharge of pollutants in water bodies. The accumulation of hazardous metals in the food chain and their dramatic effects on human and animal beings clearly explain that their control in wastewater is progressively becoming more drastic. Chromate is frequently found in industrial wastewater issued from metal finishing [1], metallurgy and tanneries (among others) at very high levels. The treatment of these contaminated waters is thus critical for these industries, for minimizing their impact on the environment and water bodies, as well as maximizing the recycling of water resources [2]. Several processes may be used, including precipitation [3], usually after

\footnotetext{
* Corresponding authors.
} 
chemical reduction to $\mathrm{Cr}$ (III) [4]), electrochemical reduction [5], or bioreduction [6]. The presence of organic compounds in acidic solutions enhances the reduction of $\mathrm{Cr}(\mathrm{VI})$ to $\mathrm{Cr}(\mathrm{III})$, which makes easy metal precipitation. Solvent-based extraction was also used directly for the recovery and the separation of chromate anions [7], but also through the impregnation of porous resins (solvent-impregnated resins [8]), or using supported hollow fiber systems [9]. Many studies have demonstrated the potential of zero-valent iron [10], iron oxide [11], and magnetitebased sorbents [12] for the removal of chromate anions. Synthetic resins (chelating [13] or ion-exchange [14,15] have been frequently used for the recovery of chromate anions. Composite beads prepared by the interactions of alginate with polyethyleneimine have also been recently designed as beads for the effective recovery of $\mathrm{Cr}(\mathrm{VI})$ [16].

Iron-based sorbents can be used making profit of both reductive and sorption abilities of these materials; but also for facilitating the solid/ liquid separation of composite sorbents when iron is incorporated as magnetic nano- or microparticles (magnetite-based sorbents [17]). Reducing the size of the sorbent usually improves the mass transfer properties. Combining with ready solid/liquid separation properties of magnetic core, this makes the material very efficient for designing new powerful sorbents [18], or antimicrobial supports [19]. The chemical versatility of the polymer may be also very useful for efficient functionalization by grafting new specific reactive groups [20-22]. Imidazole-based and thiazole-based ligands have been successfully used for improving the properties of sorbents in terms of sorption capacity and/or selectivity [23-26].

Two new sorbents have been designed and investigated in this study. Their synthesis is based on the functionalization of magnetic chitosan microparticles (MC) through the grafting of either 2-amino-4-thiazoleacetic acid (for ATA@MC) or 5-amino-4-imidazolecarboxamide (for AIC@MC). These materials are physically and chemically characterized by a wide variety of analytical techniques, before being tested for chromate sorption, first in synthetic solutions (though conventional criteria: $\mathrm{pH}$ effect, uptake kinetics, sorption isotherms, selectivity, metal desorption and sorbent recycling). In a second step, the sorption properties are tested for the treatment of an industrial wastewater collected in an Egyptian tannery unit. It is noteworthy that in acidic solutions and in the presence of organic materials [27], chromate anions are readily reduced into $\mathrm{Cr}(\mathrm{III})$, which can easily precipitate with $\mathrm{pH}$ increase. This phenomenon makes considerably more complex the interpretation of sorption mechanisms; it is difficult precisely assigning the respective contributions of $\mathrm{Cr}(\mathrm{VI})$ sorption and chromate reduction/precipitation in metal removal. The combination of metal sorption and metal reduction (with local precipitation and/or $\mathrm{Cr}(\mathrm{III})$ release into the solution) may explain this complexity $[28,29]$. Herein, FTIR and XPS analyses are used for approaching sorption mechanisms and characterizing metal reduction. Chromate removal is followed by the analysis of total $\mathrm{Cr}$ concentrations.

The diseases caused by bacterial and fungal infections represent a worldwide problem. There is a need for developing new active compounds. In the current study, the efficacy of synthesized composites was investigated as active compounds against pathogenic $\mathrm{Gram}^{+}$(Bacillus subtilis and Staphylococcus aureus), Gram ${ }^{-}$bacteria (Pseudomonas aeruginosa and Escherichia coli), and unicellular fungi (Candida albicans). Atimicrobial tests were carried out using the agar well diffusion method. Dhivya et al., [19] demonstrated the efficiency of this method for quantifying and comparing the antibacterial effects of magnetite nanoparticles (NPs) and chitosan/magnetite NPs for Escherichia coli KL226. Herein, the method was used at different doses of functionalized magnetic chitosan micro-particles to evaluate the minimum inhibition concentration (MIC), for the different types of pathogenic inoculates.

\section{Materials and methods}

\subsection{Materials}

Ferrous sulfate $\left(\mathrm{FeSO}_{4} \cdot 7 \mathrm{H}_{2} \mathrm{O}\right)$, ammonium ferric (III) sulfate dodecahydrate $\left(\left(\mathrm{NH}_{4}\right) \mathrm{Fe}\left(\mathrm{SO}_{4}\right)_{2} \cdot 12 \mathrm{H}_{2} \mathrm{O}\right)$, epichlorohydrin (EPI), 2-Amino-4thiazoleacetic acid (ATA) (95\%), 5-Amino-4-imidazolecarboxamide (AIC) (95\%), Chitosan (DA: greater than $75 \%$ ) (C), sodium hydroxide pellets (for $\mathrm{pH}$ adjustment), and potassium dichromate $\left(\mathrm{K}_{2} \mathrm{Cr}_{2} \mathrm{O}_{7}\right)$ were supplied by Sigma Aldrich (Merck, Darmstadt, Germany). Acetone and dimethylformamide (DMF) were purchased from Chron Chemicals (Qionglai, China). Other chemicals were obtained from Prolabo (VWR France (Avantor Group), Fontenay-sous-Bois, France) and used as received.

\subsection{Synthesis of sorbents}

\subsubsection{Synthesis of magnetic chitosan microparticles ( $M C^{*}$ )}

The thermal co-precipitation reaction of ferrous sulfate (i.e., FeS$\mathrm{O}_{4} \cdot 7 \mathrm{H}_{2} \mathrm{O}, 5.0 \mathrm{~g}$ ) and hydrated ammonium ferric sulfate (i.e., $\left(\mathrm{NH}_{4}\right) \mathrm{Fe}$ $\left.\left(\mathrm{SO}_{4}\right)_{2} \cdot 12 \mathrm{H}_{2} \mathrm{O}, 17.35 \mathrm{~g}\right)$ in water allowed synthesizing magnetic nanoparticles (method derived from Massart [30]). After maintaining the mixture for $60 \mathrm{~min}$ at $40-50{ }^{\circ} \mathrm{C}$ (under vigorous stirring); the $\mathrm{pH}$ was controlled to $10-12$ using $5 \mathrm{M} \mathrm{NaOH}$ solution (at $45{ }^{\circ} \mathrm{C}$, for $5 \mathrm{~h}$ ). Magnetite nanoparticles were: (a) magnetically separated, (b) washed with Milli-Q water, and acetone, and (c) finally dried at $50{ }^{\circ} \mathrm{C}$, overnight. Chitosan powder (4 g) was soaked in acetic acid solution ( $150 \mathrm{~mL}, 20 \%$ $\mathrm{w} / \mathrm{w})$. Magnetite particles $(1.5 \mathrm{~g}$ ) were added to the chitosan solution. The temperature of the mixture was maintained at $45^{\circ} \mathrm{C}$, while $\mathrm{pH}$ was controlled to 10 using $5 \mathrm{M} \mathrm{NaOH}$ solution for precipitating magnetic chitosan microparticles (MC). The mixture was aged for $2 \mathrm{~h}$, at $90{ }^{\circ} \mathrm{C}$. Composite particles (MC, $5.4 \mathrm{~g}$ ) were magnetically recovered and abundantly rinsed with demineralized water. The chemical stability of the composite was improved by crosslinking: magnetic chitosan particles were mixed for $3 \mathrm{~h}$ at $47 \pm 3{ }^{\circ} \mathrm{C}$ with an alkaline $0.01 \mathrm{M}$ epichlorohydrin (EPI) solution ( $0.067 \mathrm{M} \mathrm{NaOH}$ solution; $\mathrm{pH} \sim 10)$. Here, EPI acts a crosslinker. Treated solid was recovered by magnetic separation and washed several times with acetone (to remove unreacted reagents). Treated microparticles were dried at $50{ }^{\circ} \mathrm{C}$ overnight to produce $\mathrm{MC}^{*}$ sorbent (5.44 g).

\subsubsection{Activation of $M C^{*}(M C-C l)$}

Epichlorohydrin-crosslinked MC particles (MC*) were activated by a second EPI treatment: the particles were mixed with an aqueous/ethanol solution (150 mL, 1:1) containing EPI (18 mL). In this step, EPI allows immobilizing spacer and reactive arms that facilitate further grafting of new functional groups (in the next step) through substitution reaction of chlorine with amino or thiol groups. The mixture was refluxed for $3 \mathrm{~h}$, at $70{ }^{\circ} \mathrm{C}$. The activated materials (MC- $\mathrm{Cl}, 8.3 \mathrm{~g}$ ) were magnetically separated. After ethanol and Milli-Q water washings, the material was airdried for $10 \mathrm{~h}$ at $50{ }^{\circ} \mathrm{C}$.

\subsubsection{Synthesis of AIC@MC and ATA@MC}

Two solutions were prepared by dissolving either 2-Amino-4-thiazoleacetic acid (5 g, for ATA@MC), or 5-Amino-4-imidazolecarboxamide (5 g, for AIC@MC) in DMF $(150 \mathrm{~mL})$; the solutions were controlled to pH 9.5-10 using $5 \mathrm{M} \mathrm{NaOH}$ solution. Activated $\mathrm{MC}-\mathrm{Cl}$ particles $(7 \mathrm{~g})$ were mixed to the solutions for $10 \mathrm{~h}$ at $80-85^{\circ} \mathrm{C}$ to produce functionalized sorbents (final weight: $\sim 9.8 \mathrm{~g}$ ). The products were separated by magnetic separation and dried overnight at $50{ }^{\circ} \mathrm{C}$.

Scheme 1 summarizes the different steps of the synthesis procedures for MC, MC*, MC-Cl, AIC@MC and ATA@MC.

\subsection{Characterization of materials}

$\mathrm{X}$-ray photoelectron spectrometry was used for characterizing the 

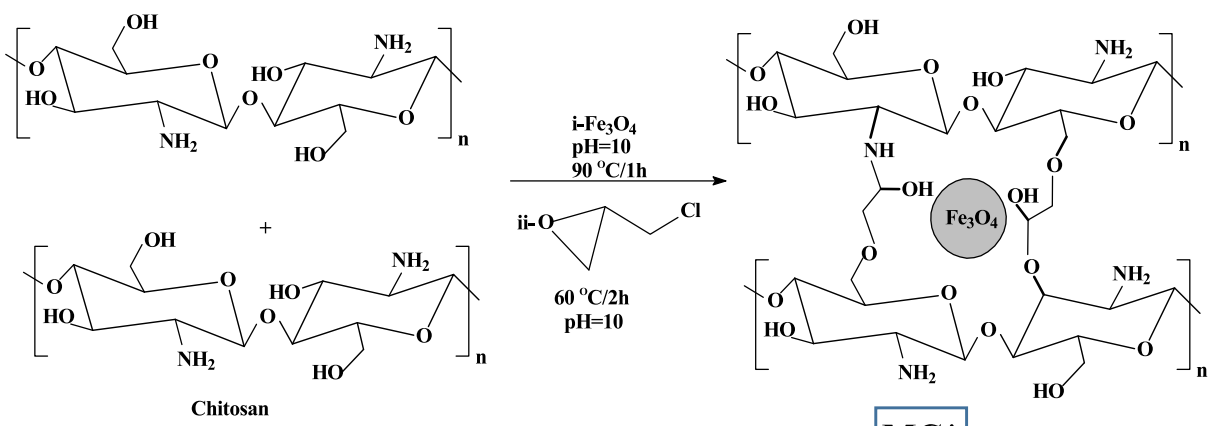

MC*
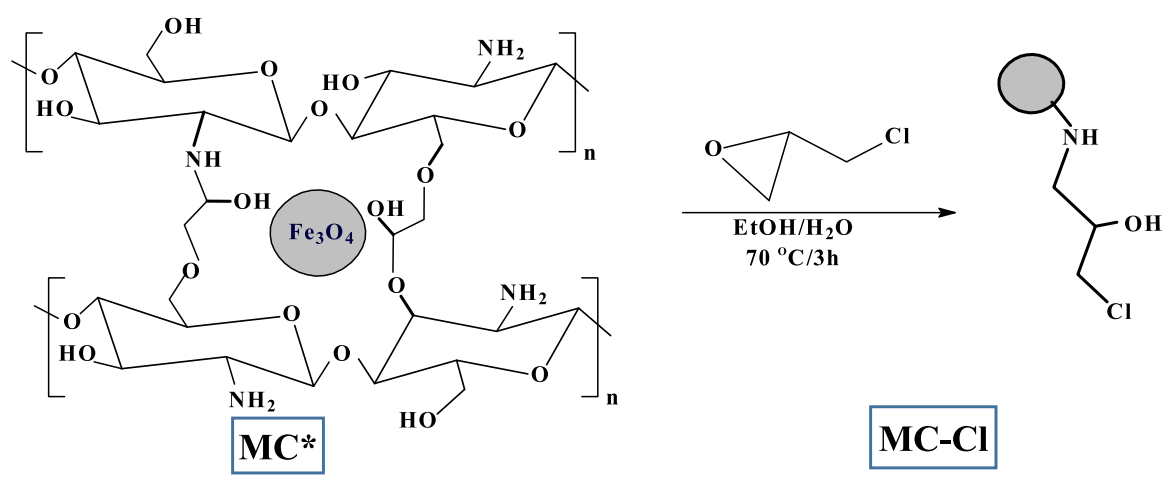

\section{MC-Cl}

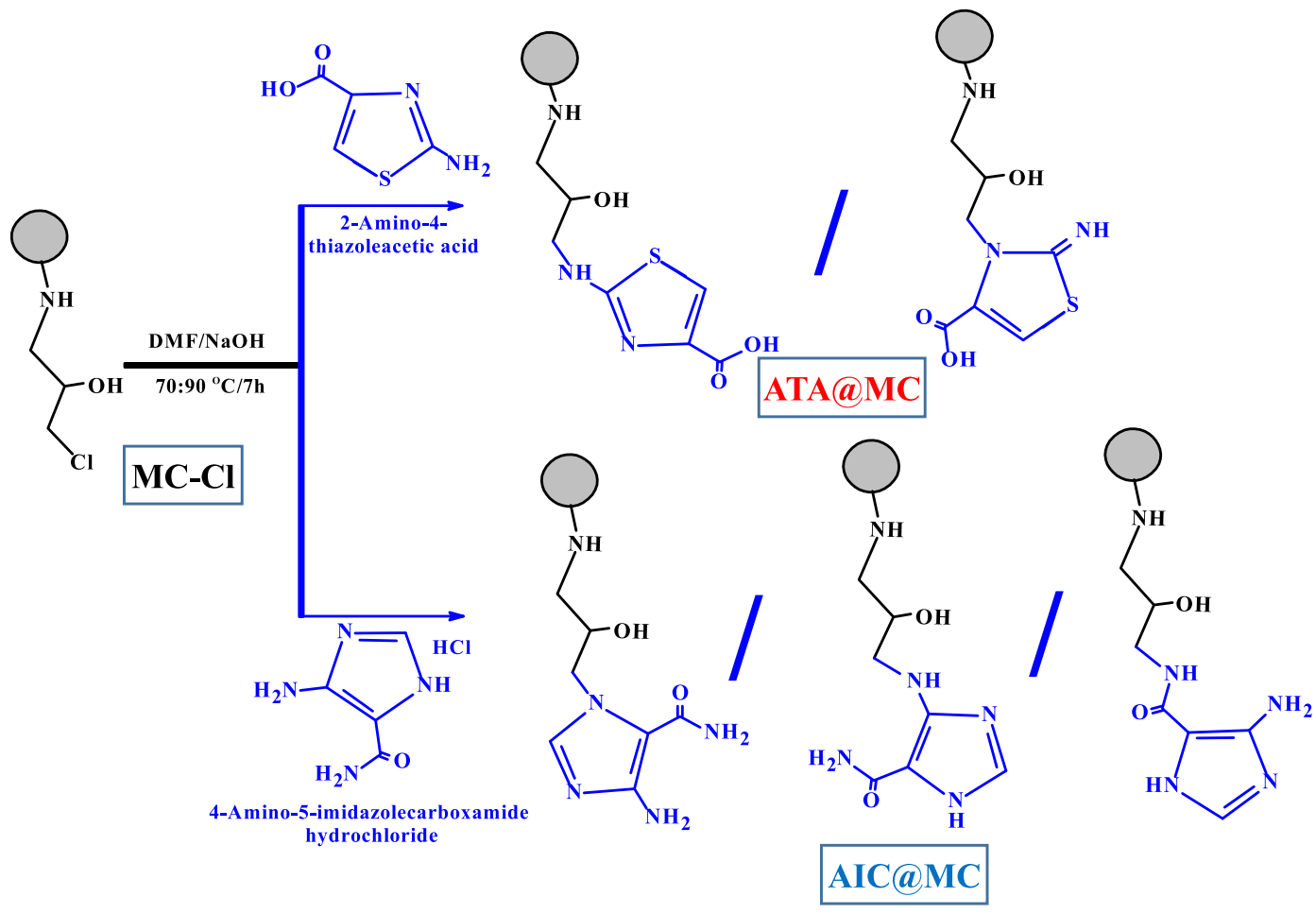

Scheme 1. Synthesis procedures for the production of sorbents.

materials (and their interactions with chromate anions); spectra were acquired by means of ESCALAB 250XI + electron spectrometer (Thermo Fischer Scientific, Inc., Waltham, MA, USA). The monochromatic $\mathrm{Al} \mathrm{K}$ $\mathrm{X}$-ray radiation $(1486.6 \mathrm{eV}$ ) was used as the excitation source; the size of the analytical spot was $500 \mu \mathrm{m}$ spot. The pressure of the analytical chamber was less than $10^{-8}$ mbar. The analyzer used a $20 \mathrm{eV}$ pass energy for the acquisition of high-resolution core-level spectra (50 eV for full spectrum analysis). The BE was calibrated using C $1 s$ at $284.8 \mathrm{eV}$ for
$\mathrm{C}_{\mathrm{adv}}, \mathrm{C}-\mathrm{C}$-, and $\mathrm{C}=\mathrm{C}$. The energy resolution on $\mathrm{Ag} 3 d_{5 / 2}$ was $0.45 \mathrm{eV}$, and $0.82 \mathrm{eV}$ for $\mathrm{C} 1 s$. FTIR spectra were acquired using the so-called $\mathrm{KBr}$ disc method using an IRTracer-100 spectrophotometer (Shimadzu, Tokyo, Japan).

A Phenom ProX scanning electron microscope (SEM, Thermo Fisher Scientific, Netherlands) coupled with EDX facilities was used for the observation of the morphology of sorbents and for their semiquantitative analysis. The textural properties of the sorbents have 
been analyzed using the BJH method and a Micromeritics TrisStar II surface analyzer (Norcross, GA, USA). The samples were degassed at $100{ }^{\circ} \mathrm{C}$ for $12 \mathrm{~h}$, prior analysis. A Netzsch STA 449 F3 Jupiter thermogravimeter was used for TGA analysis, with a temperature ramp of $10{ }^{\circ} \mathrm{C} / \mathrm{min}$ (under oxygen atmosphere) (NETZSCH-Gerätebau $\mathrm{GmbH}$, Selb, Germany). The elemental composition of the sorbents was determined using Vario EL cube element analyzer (Elementar Analysensysteme $\mathrm{GmbH}$, Langenselbold, Germany). The $\mathrm{pH}_{\mathrm{PZC}}$ values were determined by the $\mathrm{pH}$-drift method [17].

\subsection{Sorption studies}

Sorption studies were carried out in batch systems: a fixed amount of sorbent $(\mathrm{m}, \mathrm{g}$ ) was mixed with a fixed volume of solution $(\mathrm{V}, \mathrm{L})$, at room temperature (i.e., $22 \pm 1{ }^{\circ} \mathrm{C}$ ); the agitation was set to v: $210 \mathrm{rpm}$. The sorbent dose was set to $0.5 \mathrm{~g} \mathrm{~L}^{-1}$ (in most cases). For the study of $\mathrm{pH}$ effect, the initial $\mathrm{pH}$ value (i.e., $\mathrm{pH}_{0}$ ) varied between 1 and 6 ; the $\mathrm{pH}$ was not controlled during the sorption but the final $\mathrm{pH}$ (i.e., $\mathrm{pH}_{\mathrm{eq}}$ ) was recorded using a pH-26A Acculab USA pH-meter (Acculab USA, New York, USA). For equilibrium experiments (sorption isotherms, selectivity tests, etc.), the contact time was fixed to $48 \mathrm{~h}$. The initial concentration $\left(\mathrm{C}_{0}, \mathrm{mmol} \mathrm{Cr} \mathrm{L}^{-1}\right)$ was varied between 0.2 and $9.6 \mathrm{mmol} \mathrm{Cr} \mathrm{L}^{-1}$ for sorption isotherms at $\mathrm{pH}_{0}: 2$. In the case of selectivity tests, equimolar multi-component solutions ( $1 \mathrm{~mol} \mathrm{~L}^{-1}$ for $\mathrm{Ca}(\mathrm{II}), \mathrm{Cu}(\mathrm{II}), \mathrm{Cd}(\mathrm{II}), \mathrm{Zn}$ (II), $\mathrm{Ni}$ (II) and $\mathrm{Cr}(\mathrm{VI})$ ) were prepared at $\mathrm{pH}_{0}: 2.27,3.96$ and 4.55.

For uptake kinetics $\left(\mathrm{pH}_{0}: 2 ; \mathrm{C}_{0} ; 2 \mathrm{mmol} \mathrm{Cr} \mathrm{L}^{-1}\right)$, samples were collected at different contact times, and the microparticles were magnetically separated before analyzing residual metal concentration in the solution. Total chromium concentration in the solution was determined by atomic absorption spectroscopy (PerkinElmer AAnalyst 800 atomic spectrometer, Waltham, MS, USA); the respective concentrations of $\mathrm{Cr}(\mathrm{III})$ and $\mathrm{Cr}(\mathrm{VI})$ were not determined.

The amount of metal bound to the sorbent $\left(\mathrm{q}_{\mathrm{eq}}, \mathrm{mmol} \mathrm{g}^{-1}\right.$ ) was deduced from the mass balance equation: $\mathrm{q}_{\mathrm{eq}}=\left(\mathrm{C}_{0}-\mathrm{C}_{\mathrm{eq}}\right) \times \mathrm{V} / \mathrm{m}$. The distribution ratio $\left(\mathrm{D}, \mathrm{L} \mathrm{g}^{-1}\right)$ is calculated by $\mathrm{D}=\mathrm{q}_{\mathrm{eq}} / \mathrm{C}_{\mathrm{eq}}$. The desorption of chromate from loaded sorbent was operated using $0.5 \mathrm{M} \mathrm{HCl}$ solution; a water rinsing step was systematically run between each sorption and desorption steps (in the case of sorbent recycling tests). The FTIR spectra of materials exposed to five successive cycles of sorption/desorption were collected for evaluating the stability of the sorbent.

The models used for fitting experimental profiles are summarized in Table S1a for uptake kinetics, and in Table S1b for sorption isotherms (see Supplementary Information).

\subsection{Application to tannery wastewater}

The tannery wastewater was collected from 10th of Ramadan, Cairo,

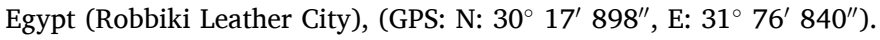
Sorption tests were performed in batch systems at two $\mathrm{pH}$ values, $\mathrm{pH}_{0}: 2$ and 5. The sorbent dose was varied between 1 and $30 \mathrm{~g} \mathrm{~L}^{-1}$. The contact time was set to $24 \mathrm{~h}$.

\subsection{Evaluation of antimicrobial effects}

The antimicrobial activity of synthesized compounds (MC, AIC@MC, ATA@MC) was investigated against $\mathrm{Gram}^{+}$bacteria (Bacillus subtilis ATCC6633, Staphylococcus aureus ATCC6538), Gram bacteria (Escherichia coli ATCC8739, Pseudomonas aeruginosa ATCC9022), and unicellular fungi (Candida albicans ATCC10231) using agar well diffusion method. About $50 \mu \mathrm{L}\left(1 \times 10^{8} \mathrm{CFU} / \mathrm{mL}\right)$ of each overnight microbial culture were inoculated separately into $100 \mathrm{~mL}$ Muller Hinton Agar media (ready-prepared - Oxoid, Thermo Fisher Diagnostics, Dardilly, France). The inoculated media was poured onto sterilized Petri-plates, under aseptic conditions. Wells $(0.7 \mathrm{~mm}$ in diameter) were prepared onto the inoculated plates before being filled with $100 \mu \mathrm{L}$ of suspension (200 $\mu \mathrm{g} / 1.0 \mathrm{~mL}$ DMSO). To detect the minimum inhibitory concentration (MIC), different concentrations (200, 100, 50, and $25 \mu \mathrm{g}$ $\mathrm{mL}^{-1}$ ) from each composite were prepared and check for their antimicrobial activity. The filled plates were kept in the refrigerator for one hour before being incubated at $35 \pm 2{ }^{\circ} \mathrm{C}$ for $24 \mathrm{~h}$. The results were recorded by measuring the diameter of the inhibition zone (ZOI) around each well [31]. A blank test was systematically performed using DMSO (alone) as the control. The ZOI was expressed as the mean \pm standard deviation of three independent replicates. Data were processed by variance analysis (ANOVA) using the statistical package SPSS v17 (IBM, Armonk, NY, USA). The comparison of average values for the different treatments was analyzed by the Tukey HSD test, at $p$ less than 0.05 .

\section{Results and discussion}

\subsection{Characterization of sorbents}

\subsubsection{Morphology and textural properties}

Figure S1 (see Supplementary Information) shows the SEM and TEM micrographs of AIC@MC and ATA@MC. The sorbents show irregular shapes with an average particle size close to $20 \mu \mathrm{m}$; the type of grafting does not significantly affect the shape and size. The TEM views confirm the embedment of magnetic nanoparticles (mNPs, dense dark objects) into the polymer matrix, the shape of these nanoparticles is not uniform; however, rounded particles predominate. The size of magnetite NPs ranges between 4 and $20 \mathrm{~nm}$. These NPs are homogeneously dispersed into the polymer matrix. Although the magnetization was not measured, Figure S2 confirms the ready separation of sorbent particles from aqueous solutions using an external magnetic field.

Table S2 reports the specific surface area $\left(\mathrm{S}_{\mathrm{BET}}\right)$ and the porous volume $\left(\mathrm{V}_{\mathrm{p}}\right)$ of both AIC@MC and ATA@MC. The type of grafting hardly affects the textural properties of the materials: $\mathrm{S}_{\mathrm{BET}}$ varies between 22.1 and $23.9 \mathrm{~m}^{2} \mathrm{~g}^{-1}$ for ATA@MC and AIC@MC, respectively; while the $\mathrm{V}_{\mathrm{p}}$ values range between 7.0 and $7.4 \mathrm{~cm}^{3} \mathrm{STP} \mathrm{g}^{-1}$.

\subsubsection{Thermogravimetric analysis}

The TGA analysis shows that MC, AIC@MC and ATA@MC have roughly the same degradation profiles (Figure S3, see detailed discussion). A first weight loss (which represents about 6\%) corresponds to the release of adsorbed water. The residue at $800{ }^{\circ} \mathrm{C}$, close to $60.8 \%$ for both AIC@MC and ATA@MC is supposed to be the magnetite fraction, which is higher than the expected content from synthesis procedure (meaning probably that a fraction of the organic fraction was not completely degraded).

\subsubsection{FTIR spectroscopy}

3.1.3.1. Synthesis of sorbents. The FTIR analysis of MC, epichlorohydrin-activated MC (MCH-Cl), and sorbents allows identifying the chemical changes occurring at the different steps of the synthesis procedure (Figure S4, Table S3, see detailed analysis). The presence of magnetite is identified by the peaks at $583-589 \mathrm{~cm}^{-1}$ and $445-452 \mathrm{~cm}^{-1}$. The typical bands of $\beta$-D-glucose unit are also observed. The activation of the composite (MC-Cl) appears through the appearance of $\mathrm{C}-\mathrm{Cl}$ bond (at $809 \mathrm{~cm}^{-1}$ ) and epoxy ring (at $1245 \mathrm{~cm}^{-1}$ ). These peaks disappear after functionalization. Primary bending band is reinforced for AIC@MC, while the differences are less marked for ATA@MC.

3.1.3.2. FTIR spectroscopy for characterization of chromate interactions with sorbents. The FTIR spectra of the sorbents are affected by chromate sorption (Fig. 1, Tables S4a and S4b), leading to:

(a) shifts of the $-\mathrm{OH}$ and $-\mathrm{NH}$ stretching vibrations from 3353 and $3346 \mathrm{~cm}^{-1}$ for AIC@MC and ATA@MC, respectively, to 3358 and 3362 $\mathrm{cm}^{-1}$,

(b) shifts of $\mathrm{C}=\mathrm{O}$ amide stretching and binding vibrations of amine groups (from 1652 to $1651 \mathrm{~cm}^{-1}$ to 1643 or $1633 \mathrm{~cm}^{-1}$ ), 


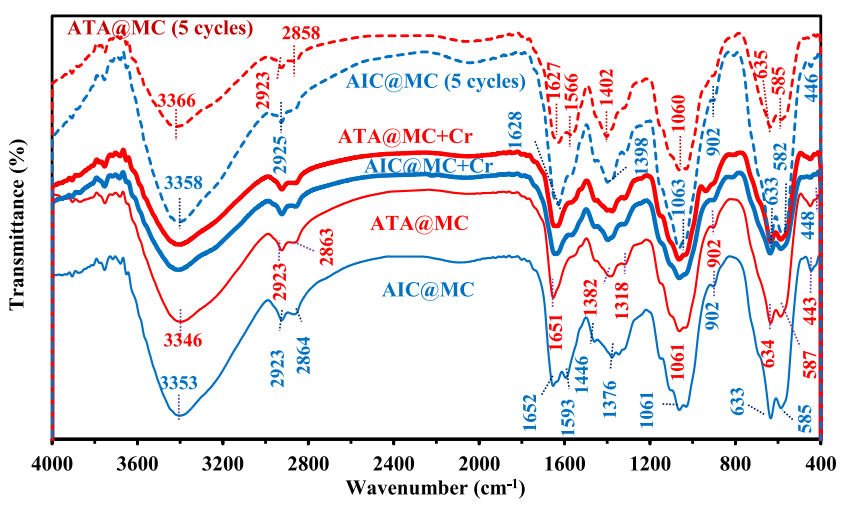

Fig. 1. FTIR spectra of AIC@MC, ATA@MC, before and after metal sorption (and after 5 cycles of sorption and desorption).

(c) shifts of $-\mathrm{OH}$ bending, and $\mathrm{COO}^{-}$salt (from 1376 to $1382 \mathrm{~cm}^{-1}$ to $1397-1398 \mathrm{~cm}^{-1}$ ),

(d) the strong decrease of the band at $1594 \mathrm{~cm}^{-1}$ (for AIC@MC, NHamide II band), consistently with the results reported for chromate sorption onto chitin [32].

It is noteworthy that chromate typical FTIR vibrations (Cr-O stretching vibration) are reported in the wavenumber range 950-800 $\mathrm{cm}^{-1}$ [33]. Apparently, this signal overlaps with other signal associated with $\beta$-D-glucose unit, $\mathrm{CH}_{2}$ rocking.

Several reactive groups may be involved in chromate binding including $-\mathrm{OH},-\mathrm{NH}$, and $-\mathrm{C}=\mathrm{O} /-\mathrm{COO}$ - groups.

The spectra of the sorbents after five cycles of sorption and desorption of chromate are also reported in Fig. 1 (and Tables S4a and S4b). Despite the efficient desorption of chromate (see Section 3.2.5.), the FTIR spectra of the sorbents are significantly affected. The spectra are not fully restored after metal desorption: the wavenumbers are shifted compared with initial spectra and the peaks are located at the same wavenumbers reported after chromate sorption. This means that the sorption and desorption cycles are slightly modifying the chemical structure of the sorbents. Chromate anions in acidic solutions oxidize some reactive groups at the surface of the sorbent, as a corollary of the partial reduction of $\mathrm{Cr}(\mathrm{VI})$ into $\mathrm{Cr}(\mathrm{III})$ (see Section 3.1.4.). However, these chemical modifications do not drastically change $\mathrm{Cr}$ (VI) sorption performances (Section 3.2.5.). The changes in the FTIR spectra after chromate sorption may cover both the interactions of chromate anions with reactive groups the changes referring to the oxidation of reactive groups.

Chromate anions may exist in the solution under different forms (as mentioned in Figure S5 - Cr(VI) speciation diagram under the experimental conditions selected for the study of $\mathrm{pH}$ effect). At the surface of the sorbent, chromate may also appear as monomeric and dimeric species. However, the chromate species are supposed to appear in the range $950-770 \mathrm{~cm}^{-1}[34,35]$, where the region is affected by the superposition of the contributions of several other reactive groups; making difficult the detailed discussion of this mechanism.

\subsubsection{XPS spectroscopy for characterization of chromate interactions with sorbents}

Fig. 2 compares the XPS survey curves for AIC@MC and ATA@MC sorbent before and after $\mathrm{Cr}(\mathrm{VI})$ sorption. Raw sorbents are characterized by the presence of Fe peaks (Fe 3p, Fe $2 p$ signals) from magnetite NPs), C $1 s, \mathrm{O} 1 s$ and $\mathrm{N} 1 s$ peaks from polymer coating. The functionalization of the composite is clearly identified for ATA@MC by the appearance of the $\mathrm{S} 2 p$ signal. After chromate sorption, chromium signal appears (as $\mathrm{Cr} 2 p$, $\mathrm{Cr} 2 s$, and $\mathrm{Cr} 3 p$ signals). It is noteworthy that after chromate sorption, Ca $2 p$ and Ca $2 s$ signals appear (especially for ATA@MC).

The HRES spectra are reported in Figures S6 and S7 before and after Cr(VI) sorption for AIC@MC and ATA@MC, respectively. Table S5

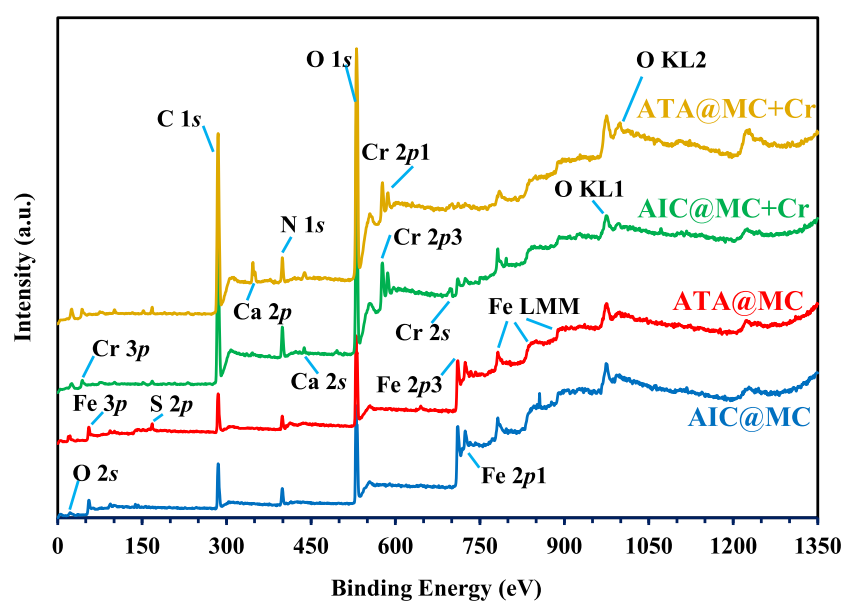

Fig. 2. XPS survey of AIC@MC and ATA@MC before and after chromate sorption.

summarizes the binding energy (BE, eV) and atomic fraction ( $\mathrm{AF}, \%$ ) for the main signals, with their assignments. The sorption of chromate anions is mainly followed by: (a) the changes in relative contributions of the different bonds, (b) the shifts in BEs, as tracers of the involvement of reactive groups in the binding of metal anions, and/or the chemical modifications of reactive groups (associated with the reduction of $\mathrm{Cr}(\mathrm{VI})$ and the oxidation of the sorbents). For $\mathrm{C} 1 s$, the BEs are stable, while the AFs of $\mathrm{C}=\mathrm{O}$ and $\mathrm{O}=\mathrm{C}-\mathrm{N}$ slightly increases (contrary to $\mathrm{C}-\mathrm{N}, \mathrm{C}-\mathrm{O}$ and $\mathrm{C}-\mathrm{S}$ signals that weakly decrease). In the case of $\mathrm{O} 1 \mathrm{~s}$ signal, the most significant changes concern the strong variation in the AFs of the different functional groups. The shape of the $\mathrm{O} 1 s$ spectra strongly changes for both AIC@MC and ATA@MC. This may be explained by (a) the appearance of $\mathrm{O}-\mathrm{Cr}$ bond, (b) the modification of the environment of $\mathrm{C}=\mathrm{O} / \mathrm{O}=\mathrm{C}-\mathrm{O}($ at $\sim 531.5 \mathrm{eV}$ ) and $\mathrm{C}-\mathrm{O} / \mathrm{C}-\mathrm{OH}$ (at $\sim 532.7 \mathrm{eV}$ ) signals (interactions with), and/or (c) the chemical modification of these reactive groups (oxidation of surface groups by chromate anions in acidic solutions). Apparently, the contribution of $\mathrm{Fe}-\mathrm{O}$ (from magnetite) is decreased after chromate sorption, for the two sorbents; this is probably associated with the shift of other signals and the chemical modifications of reactive groups that minimize the relative intensity of the signal of magnetite. Significant changes in the contributions of the different components of $\mathrm{N} 1 s$ signal are also observed after metal binding. The sorbents bind chromate from acidic solutions: the contribution of protonated amine groups increases (at $\sim 401.8 \mathrm{eV}$ ), as well as $\mathrm{N}-\mathrm{H}$ (at $\sim 400.2 \mathrm{eV}$ ), while that of $>\mathrm{N}=,-\mathrm{NH}_{2}, \mathrm{~N}-\mathrm{C}$ and $\mathrm{N}-\mathrm{S}$ (at $\sim 399 \mathrm{eV}$ ) decreases (being shifted to $399.7 \mathrm{eV}$ in the case of AIC@MC). These strong changes in the environment of $\mathrm{O}$ - and $\mathrm{N}$-bearing groups clearly confirm the involvement of the relevant functional groups in the uptake of chromate anions (consistently with FTIR observations). Another important information is provided by the deconvolution of $\mathrm{Cr} 2 p_{3 / 2}$ signal: two forms of chromium coexist as $\mathrm{Cr}$ (III) (the predominant form) and $\mathrm{Cr}(\mathrm{VI})$. This is a clear demonstration that chromate reduces into $\mathrm{Cr}$ (III) during (or after) metal binding (different forms of $\mathrm{Cr}(\mathrm{III})$ may be present on the sorbents: oxides, hydroxides or $\mathrm{N}-\mathrm{Cr}$ ). The two sorbents have comparable reducing effect (based on the values of $\mathrm{Cr}(\mathrm{VI})$ and $\mathrm{Cr}$ (III) AFs). The analysis of S $2 p$ signal confirms the presence of sulfur in ATA@MC (thiazole moiety); however, the deconvolution of the signal shows that apart this organic form of S element, sulfate may be also present at the surface of the sorbent. This may be due to the sorption of sulfate anions (resulting from sulfuric acid, used for $\mathrm{pH}$ control), or chromosulfuric forms (speciation of chromate anions in sulfuric acid solutions).

Scheme 2 shows the mechanisms possibly involved in the sorption of chromate onto the two sorbents. Most of the interactions concern ionic interactions (anion exchange) between protonated amine groups and 


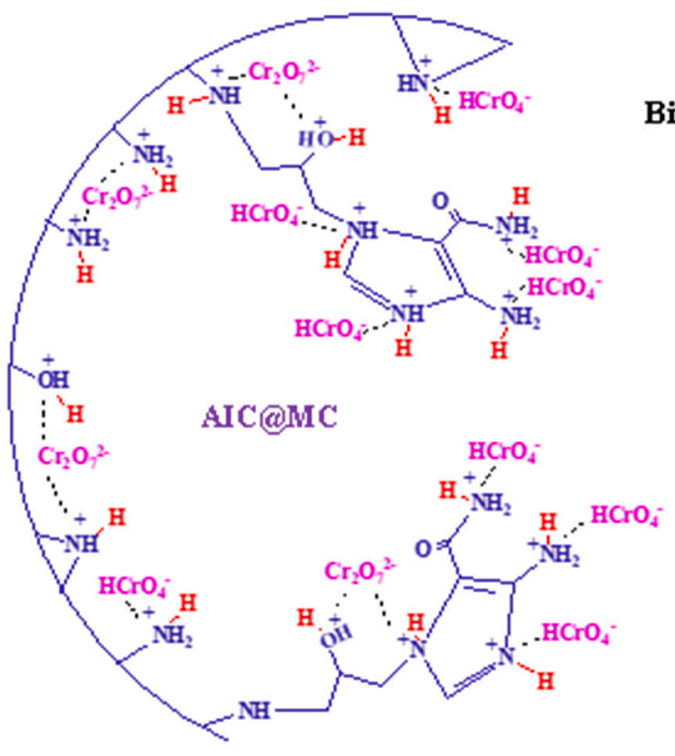

Binding Mechanisms

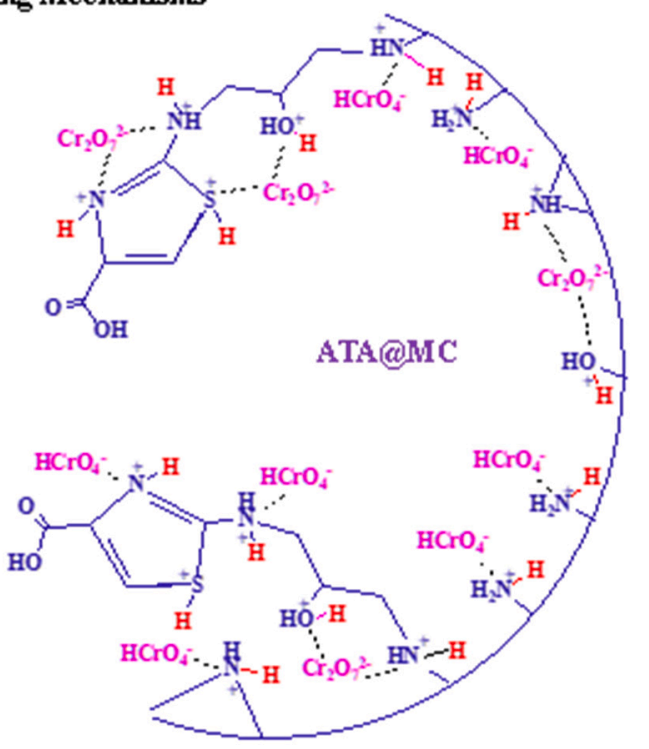

Scheme 2. Tentative mechanisms for the sorption of chromate anions onto AIC@MC and ATA@MC.

chromate anionic species $\left(\mathrm{HCrO}_{4}^{-}\right.$and $\left.\mathrm{Cr}_{2} \mathrm{O}_{7}{ }^{2-}\right)$ with contributions of hydroxyl groups for the stabilization of bonds and/or sulfur groups (for ATA@MC). The hydroxyl groups present on the sorbent may also contribute to metal binding through anion exchange. However, in acidic solutions (such as selected conditions), this contribution is rather limited compared to the reactive groups grafted on magnetic-chitosan support. In acidic solution, the protonation of $\mathrm{OH}$ groups may contribute to attract chromate anions. The contribution of anion exchange mechanism is expected to be more significant at higher $\mathrm{pH}$ values where the sorbent is less protonated. It is noteworthy that complementary mechanisms of reduction are simultaneously occurring; this makes more complex the global interpretation of interaction modes.

\subsubsection{Chemical analysis - elemental analysis}

Table S6 reports the chemical analysis of the three sorbents. For MC material the nitrogen content is close to $4.54 \%(\mathrm{w} / \mathrm{w})$, corresponding to nitrogen molar content of $3.24 \mathrm{mmol} \mathrm{g}^{-1}$. The molecular weight of the equivalent unit of chitosan depends on the degree of deacetylation (DDA) of the polymer. However, for most commercial chitosan sample with a DDA of $85 \%$, the $\mathrm{N}$ content is close to $5.5 \mathrm{mmol} \mathrm{N} \mathrm{g}^{-1}$. This means that magnetite content in the composite may be close to $41 \%(\mathrm{w} / \mathrm{w})$. The $\mathrm{Cl}$ content into epichlorohydrin-activated MC is close to $5.23 \%(\mathrm{w} / \mathrm{w})$, corresponding to $1.17 \mathrm{mmol} \mathrm{Cl} \mathrm{g}^{-1}$; the $\mathrm{Cl} / \mathrm{N}$ ratio is close to 0.36 : only one-third of amine groups is activated with epichlorohydrin.

The grafting of 4-amino-5-imidazolecarboxamide (AIC) onto epichlorohydrin-activated MC significantly increases the fraction of nitrogen in the sorbent (up to $8.71 \%$, meaning $6.22 \mathrm{mmol} \mathrm{N} \mathrm{g}^{-1}$ ); this corresponds to a factor 1.92. Taking into account the chemical composition of the grafted molecule (i.e., $4 \mathrm{~N}$ moieties per molecule), the total conversion would correspond to factor 5 ; this means that the substitution degree (compared to $\mathrm{N}$ moieties) is close to $38 \%$. This is close to the ratio of activation of amine groups (i.e., $36 \%$ ); meaning that almost all the activated amine groups are substituted.

In the case of the grafting of 2-amino-4-thiazoleacetic acid (ATA), the increase in $\mathrm{N}$ content does not exceed $1 \%(\mathrm{w} / \mathrm{w})$ : the sorbent contains $3.96 \mathrm{mmol} \mathrm{N} \mathrm{g}^{-1}$ (instead of $3.24 \mathrm{mmol} \mathrm{N} \mathrm{g}^{-1}$ ). The $\mathrm{N}$ content (in molar units) is only increased by $22 \%$, while the full conversion would result in factor 3: the yield of substitution is close to only $7 \%$. This is roughly consistent with the $\mathrm{S}$ content in the sorbent, which is close to $0.35 \mathrm{mmol}$
$\mathrm{S} \mathrm{g}^{-1}$ (representing about $11 \%$ of the amine groups initially present on $\mathrm{MC}$ ). Referring to the rate of activation of amine groups (36\%, i.e., 1.17 mmol g$\left.{ }^{-1}\right)$, the increase in $\mathrm{N}$ content $\left(0.72 \mathrm{mmol} \mathrm{N} \mathrm{g}^{-1}\right.$, corresponding to $0.36 \mathrm{mmol} \mathrm{ATA} \mathrm{g}^{-1}$ ) means that only $31 \%$ of activated groups have been finally substituted. The grafting procedure for ATA compound is much less efficient than for AIC derivative. The semi-quantitative EDX analysis shows disappearance of $\mathrm{Cl}$ in the modified sorbents (Table S7). It is noteworthy that the values of the molar ratios are lower than expected (based on the amount present in the reaction medium and $\mathrm{CH}_{2} \mathrm{Cl}$ groups). The reagent did not fully react. The moiety $\mathrm{CH}_{2} \mathrm{Cl}$ may react through $\mathrm{S}$ and $-\mathrm{NH}$ sites. The difference in the electronegativity of $\mathrm{N}, \mathrm{O}$, and $S$ may cause intra-rearrangements (see Scheme 1). Therefore, these rearrangements may block some reactive groups (which, in turn, may limit the reactivity of functional groups). The appearance of $S$ signal confirms the successful grafting of thiazole moiety. Table S8 shows the appearance of $\mathrm{Cr}$ signal after metal binding; the binding of chromium is also accompanied by the presence of potassium for both AIC@MC and ATA@MC (Table S9).

\subsubsection{Surface charge analysis $-p H_{P Z C}$}

Scheme 1, which describes the synthesis procedure, also identifies different tautomeric structures associated with the imidazole and thiazole rings and different modes of grafting on epichlorohydrin-activated MC. These different forms may obviously affect the acid-base properties of the sorbents. Figure S8 compares the titration profiles for MC, AIC@MC, and ATA@MC, using the pH-drift method. The chemical modification is reflected by the shift of the $\mathrm{pH}_{\mathrm{PZC}}$ of the MC support: from 6.27 to 5.66 for AIC@MC and down to 4.84 for ATA@MC. The ATA substituent bearing a carboxylic acid group, the sorbent derived from ATA grafting is logically more acid. The $\mathrm{pK}_{\mathrm{a}}$ of imidazole is close to 7 , its substitution and tautomeric re-organization may both change the relevant values of $\mathrm{pK}_{\mathrm{a}}$. Hence, for AIC the $\mathrm{pKa}_{\mathrm{s}}$ values are close to 5.26 and 12.74. The $\mathrm{pK}_{\mathrm{a}}$ of 2-amino-5-thioazoleacetic acid (ATA) was reported close to 3.2 ( 2.5 for thiazole).

Obviously, the grafting on epichlorohydrin-activated MC support affects the acid-base properties and the dissociation of active groups. However, these values give some trends to explain the progressive increase in the acidity of the modified sorbents: MC $<$ AIC@MC $<$ ATA@MC. 
The maximum $\mathrm{pH}$ variation (which represents $+0.8-0.8 \mathrm{pH}$ unit, under selected experimental conditions) is detected in the range $\mathrm{pH}_{0} 3-4$ for the acidic range, and between -0.7 and -1.2 for $\mathrm{pH}_{0} 7-10$, in the alkaline region.

\subsection{Sorption properties in synthetic solutions}

\subsection{1. $p H$ effect}

The $\mathrm{pH}$ may affect not only the dissociation of the reactive groups at the surface of the sorbent but also the speciation of metal ions (including their precipitation) in the solution; as shown in Figure S8 (distribution of chromate species under the experimental conditions selected for the study of $\mathrm{pH}$ effect). Anionic species largely predominate under the following forms: $\mathrm{HCrO}_{4}{ }^{-} \gg \mathrm{CrO}_{3} \mathrm{SO}_{4}{ }^{2-}$ (negligible above $\mathrm{pH}$ 2) and $\mathrm{Cr}_{2} \mathrm{O}_{7}{ }^{2-}$. Above $\mathrm{pH} 5, \mathrm{CrO}_{4}{ }^{2-}$ appears and begins to predominate, above $\mathrm{pH}$ 6.46. Investigating the effect of $\mathrm{pH}$ is critical for optimizing the process, but this is also a useful tool for the interpretation of sorption mechanisms (as a complement of analytical procedures). Fig. 3 compares the effect of equilibrium $\mathrm{pH}$ (i.e., $\mathrm{pH}_{\mathrm{eq}}$ ) on the sorption capacity for the three sorbents. First, the superposition of duplicated experiments confirms the reproducibility of sorption tests. The maximum sorption capacity is systematically reached around $\mathrm{pH}_{\mathrm{eq}} 2-2.5$. The chemical grafting of AIC and ATA substituents strongly increases the maximum sorption capacity from $1.07 \pm 0.04 \mathrm{mmol} \mathrm{Cr} \mathrm{g}^{-1}$ for MC to $2.99 \pm 0.08$

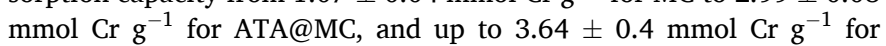
AIC@MC.

The sorption capacity increases with the $\mathrm{pH}$ up to the optimum $\mathrm{pH}$ value with a steeper slope than the decreasing trend observed above $\mathrm{pH}$ 2-2.5. In acidic conditions, the sorbents are systematically positivelycharged: protonated amine groups for MC, carboxamide, residual amine and imidazole groups for AIC@MC, and thiazole and residual amine groups for ATA@MC (carboxyl groups being under the form of carboxylic acid). These conditions make the sorbents more favorable to the binding of metal anions, such as chromate (see above for predominating species). However, the competition of the counter anions in the acid solution may impart an inhibiting effect that counterbalances the affinity of positively-charged sites for chromate species. The caption of Figure S5 also shows the concentration of competing anionic sulfate (and hydrogen sulfate) species in the solution as a function of $\mathrm{pH}$ : competitor anionic species predominate (compared with chromate species) below $\mathrm{pH} 2.5$. The affinity of the sorbents for chromate is thus the balance between the antagonist effects of anion competition and the positive charge of the sorbents. With increasing the $\mathrm{pH}$, the competition effect decreases, while the sorbent remains positively-charged and favorable for chromate sorption. At $\mathrm{pH}$ higher than 2.5, the positive charge tends to decrease due to the progressive dissociation of some reactive groups, such as secondary and tertiary amines, thiazole and/or

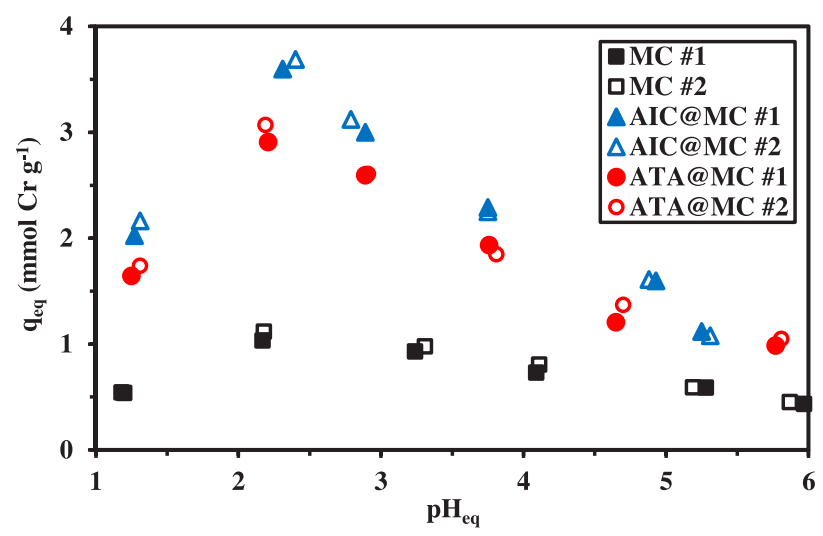

Fig. 3. Effect of $\mathrm{pH}$ on $\mathrm{Cr}(\mathrm{VI})$ removal using MC, AIC@MC, and ATA@MC (Sorbent dose, SD: $0.5 \mathrm{~g} \mathrm{~L}^{-1}$; $\mathrm{C}_{0}: 100 \mathrm{mg} \mathrm{Cr} \mathrm{L}{ }^{-1}$; time: 48 h, v: 210 rpm; T: $22 \pm$ $\left.1{ }^{\circ} \mathrm{C}\right)$. carboxylic acid groups. Therefore, the sorption of chromate anions tends to decrease.

It is noteworthy that despite the decrease in sorption properties with $\mathrm{pH}$ increase, the sorbents maintain non-negligible sorption at $\mathrm{pH}$ 5.3-6: $0.44 \pm 0.01 \mathrm{mmol} \mathrm{Cr} \mathrm{g}^{-1}$ for MC, $1.1 \pm 0.02 \mathrm{mmol} \mathrm{Cr} \mathrm{g}^{-1}$ for AIC@MC, and $1.02 \pm 0.03 \mathrm{mmol} \mathrm{Cr} \mathrm{g}^{-1}$ for ATA@MC. This means that despite the deprotonation of some reactive groups (reflected by the change in the overall charge of the sorbents, see $\mathrm{pH}_{\mathrm{PZC}}$ ), chromate anions are bound through different binding mechanisms involving chelation onto imidazole (or thiazole), amine, and/or carboxylic groups, or anion-exchange with hydroxyl groups.

It is noteworthy that the standard electrode potential $\left(\mathrm{E}^{\circ}, \mathrm{mV}\right)$ of $\mathrm{Cr}_{2} \mathrm{O}_{7}{ }^{2-} / \mathrm{Cr}^{3+}$ is relatively high and the oxidizing effect of chromate ions is strongly enhanced by acidic solutions, according to:

$\mathrm{Cr}_{2} \mathrm{O}_{7}^{2-}+14 \mathrm{H}^{+} \leftrightarrow 2 \mathrm{Cr}^{3+}+7 \mathrm{H}_{2} \mathrm{O}\left(E^{0}=+1.33 \mathrm{~V}\right)$

Therefore, chromate may contribute to the oxidation of sorbent surface, which, in turn, involves the reduction of chromate anions to $\mathrm{Cr}$ (III). This may partly contribute to the removal of chromium from the solution, especially in acidic conditions [36,37]. Though this specific aspect was not investigated, reduction-coupled sorption may be involved in the binding mechanisms. Vieira et al., [38] reported the partial reduction of chromate on different types of chitosan membranes. Imidazole and relative compounds were used for reducing metal ions or reduce the fermi potential of silver particles [39], while thiazole-based agents were used as corrosion inhibitors [40].

Sorption processes frequently affect the $\mathrm{pH}$ of the solution; Figure S9a shows that the equilibrium pH slightly increases in the case of MC (by less than $0.3 \mathrm{pH}$ unit), while functionalized sorbents tend to slightly decrease (by less than $0.3 \mathrm{pH}$ unit) the final $\mathrm{pH}$ above 3 (being slightly increased when $\mathrm{pH}_{0}$ was below 3 , consistently with $\mathrm{MC}$ ). In the $\mathrm{pH}$ range selected for further studies (i.e., $\mathrm{pH}_{0}: 2$ ), the $\mathrm{pH}$ of the solution after sorption increases in most cases by less than $0.2 \mathrm{pH}$ unit. This is roughly consistent with the $\mathrm{pH}$ variation observed in the case of $\mathrm{pH}$-drift method (for the determination of $\mathrm{pH}_{\mathrm{PZC}}$, though here the sorbent dose, $\mathrm{SD}$, was much lower). The $\mathrm{pH}$ increase means that protons directly bind on the sorbents or that chromium is bound as $\mathrm{HCrO}_{4}^{-}$. Figure $9 \mathrm{~b}$ plots the distribution coefficient $\mathrm{D}\left(\mathrm{L} \mathrm{g}^{-1}\right)$, as $\mathrm{D}=\mathrm{q}_{\mathrm{eq}} / \mathrm{C}_{\mathrm{eq}}$, in $\log _{10}$ units as a function of equilibrium $\mathrm{pH}$. The curves may be divided into two linear sections, intersecting in the range $\mathrm{pH}_{\mathrm{eq}} 2-2.5$ (corresponding to optimum $\mathrm{pH}$ values). The slopes of the left curves (acidic media) are +0.38 , +1.00 , and +0.67 for MC, AIC@MC and ATA@MC, respectively. On the other hand, the slopes for the right side are $-0.15,-0.37$, and -0.26 . For ion-exchange processes, the slope of $\mathrm{D} v s$ proton concentration (in $\log _{10}$ units) is usually associated with the ion-exchange stoichiometric ratio (both in terms of binding and release mechanisms; i.e., left/right side). The variations in the slope illustrate the changes in the sorption mechanism associated with different reactive groups, rather than metal species. Indeed, the speciation diagram clearly shows that under selected experimental conditions $\mathrm{HCrO}_{4}^{-}$is largely predominant over most of the pH range. In the case of AIC@MC, the stoichiometric ratio, in the acidic region, is close to 1 meaning that $\mathrm{HCrO}_{4}{ }^{-}$is bound through a 1:1 ion exchange mechanism. On the opposite hand, for ATA@MC the stoichiometric ratio is close to 0.67 corresponding to a $2: 3$ exchange ratio.

\subsubsection{Uptake kinetics}

The uptake kinetics are reported in Fig. 4, the equilibrium is reached within $60 \mathrm{~min}$ of mixing under selected experimental conditions, regardless of the sorbent. Taking into account the size of sorbent particles (i.e., $20 \pm 8 \mu \mathrm{m}$ ), faster kinetics would be expected; this probably means that mechanisms of resistance to diffusion are involved in the control of uptake kinetics. The textural analysis showed that the sorbents have weak specific surface area and pore volume. The sorbents being poorly porous, the diffusion of metal ions through polymer layers 


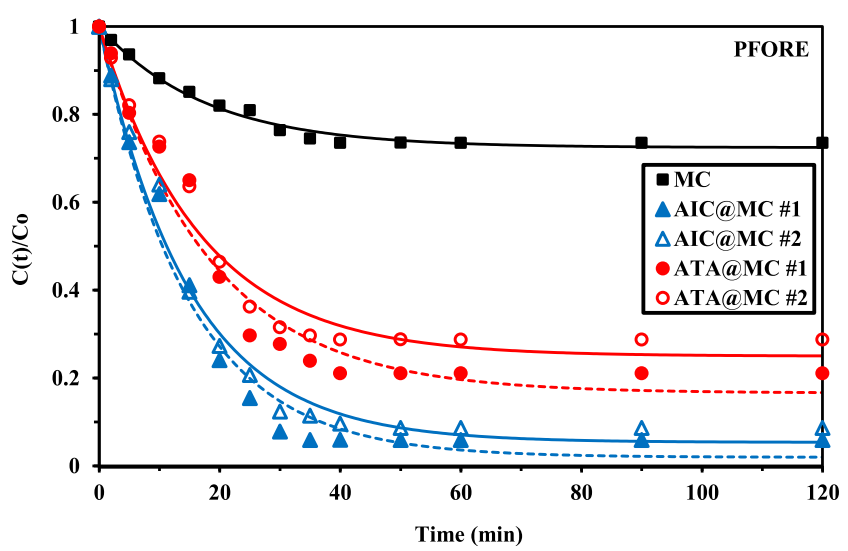

Fig. 4. $\mathrm{Cr}(\mathrm{VI})$ uptake kinetics using MC, AIC@MC, and ATA@MC - Modeling with the PFORE (SD: $0.5 \mathrm{~g} \mathrm{~L}^{-1} ; \mathrm{C}_{0}: 2 \mathrm{mmol} \mathrm{Cr} \mathrm{L}{ }^{-1}$; v: $210 \mathrm{rpm}, \mathrm{T}: 22 \pm 1{ }^{\circ} \mathrm{C}$ ).

may hinder the mass transfer of chromate anions. The modeling of kinetic profiles was tested using the equations reported in Table S1a; Table 1 summarizes the parameters of these models. The comparison of determination coefficients, AIC parameters, and equilibrium sorption capacities (calculated $v s$. experimental values) for the different models confirms that the PFORE (pseudo-first order rate equation) fits better experimental profiles than the PSORE (pseudo-second order rate equation) and the RIDE (resistance to intraparticle diffusion). In Fig. 4, the solid lines represent the fits of experimental profiles with the PFORE modeling. Interesting discussions have been published on the interpretation of sorption kinetic modeling by Simonin [41] and Hubbe [42]. These works highlighted the importance of selecting appropriate experimental conditions to be able to conclude on the type of mechanism (physical $v s$. chemical sorption) effectively involved in the control of kinetic profiles. Frequently, uncontrolled design of experiments may lead to preferential fitting with the PSORE, whereas the system is factually controlled by the resistance to intraparticle diffusion. Therefore, these modeling should be rather considered as a first approach and a tool to objectively compare the kinetic curves for the different sorbents. Herein, Table 1 confirms the good reproducibility in uptake kinetics for functionalized materials: duplicated experiments show relatively good superposition of profiles, and good stability in kinetic parameters. As expected (from the study of $\mathrm{pH}$ effect), the removal of chromate increases according the series: MC $\ll$ ATA@MC $<$ AIC@MC, based on equilibrium sorption capacities. The kinetic parameter $\left(\mathrm{k}_{1}\right)$ weakly varies with the type of sorbent, in the range 5.5-6.8 $\times 10^{-2}$ $\mathrm{min}^{-1}$. The other models do not fit correctly the experimental profiles, especially in the region of highest curvature corresponding to $15-30 \mathrm{~min}$ of contact (Figure S10). The RIDE can be used to approach the apparent

Table 1

Modeling of Cr(VI) uptake kinetics for MC, AIC@MC, and ATA@MC sorbents at $\mathrm{pH}_{0} 2$.

\begin{tabular}{|c|c|c|c|c|c|c|c|}
\hline \multirow[t]{2}{*}{ Model } & \multirow{2}{*}{$\frac{\text { Sorbent }}{\text { Parameter }}$} & \multirow[t]{2}{*}{$\mathrm{MC}$} & \multirow[b]{2}{*}{ Run \# } & \multicolumn{2}{|c|}{ AIC@MC } & \multicolumn{2}{|c|}{ ATA@MC } \\
\hline & & & & 1 & 2 & 1 & 2 \\
\hline Exper. & $\mathrm{q}_{\text {eq,exp. }}$ & 1.067 & & 3.797 & 3.775 & 3.180 & 2.949 \\
\hline \multirow[t]{4}{*}{ PFORE } & $\mathrm{q}_{\mathrm{eq}, 1}$ & 1.11 & & 3.96 & 3.91 & 3.36 & 3.11 \\
\hline & $\mathrm{k}_{1} \times 10^{2}$ & 5.65 & & 6.80 & 6.71 & 5.50 & 5.96 \\
\hline & $\mathrm{R}^{2}$ & 0.988 & & 0.984 & 0.987 & 0.969 & 0.975 \\
\hline & AIC & -124 & & -82 & -87 & -77 & -77 \\
\hline \multirow[t]{4}{*}{ PSORE } & $\mathrm{q}_{\mathrm{eq}, 2}$ & 1.33 & & 4.66 & 4.62 & 4.07 & 3.72 \\
\hline & $\mathrm{k}_{2} \times 10^{2}$ & 4.83 & & 1.71 & 1.70 & 1.46 & 1.79 \\
\hline & $\mathrm{R}^{2}$ & 0.969 & & 0.946 & 0.961 & 0.940 & 0.953 \\
\hline & AIC & -110 & & -43 & -71 & -69 & -68 \\
\hline \multirow[t]{3}{*}{ RIDE } & $D_{e} \times 10^{13}$ & 11.2 & & 1.86 & 2.49 & 4.46 & 6.20 \\
\hline & $\mathrm{R}^{2}$ & 0.971 & & 0.935 & 0.944 & 0.925 & 0.933 \\
\hline & AIC & -109 & & -61 & -64 & -64 & -63 \\
\hline
\end{tabular}

Units: $\mathrm{q}_{\mathrm{i}}: \mathrm{mmol} \mathrm{g}^{-1} ; \mathrm{k}_{1}: \min ^{-1} ; \mathrm{k}_{2}: \mathrm{L} \mathrm{mmol}^{-1} \min ^{-1} ; \mathrm{D}_{\mathrm{e}}: \mathrm{m}^{2} \mathrm{~min}^{-1}$. diffusivity $\left(D_{e}\right)$. The values are less reproducible compared with PFORE and PSORE kinetic parameters: a greater dispersion is observed while duplicating the kinetic profiles. The diffusion of chromate follows the series: MC $\left(1.1 \times 10^{-12} \mathrm{~m}^{2} \mathrm{~min}^{-1}\right)>$ ATA@MC $\left(4.5-6.2 \times 10^{-13} \mathrm{~m}^{2}\right.$ $\left.\min ^{-1}\right)>$ AIC@MC $\left(1.9-2.5 \times 10^{-13} \mathrm{~m}^{2} \mathrm{~min}^{-1}\right)$. These values are several orders of magnitude lower than the self-diffusivity of chromate in water (i.e., $6.79 \times 10^{-8} \mathrm{~m}^{2} \mathrm{~min}^{-1}$, [43]); this means that the resistance to intraparticle diffusion cannot be neglected in the control of $\mathrm{Cr}(\mathrm{VI})$ uptake kinetics. Anyway, on a practical point of view, the equilibrium time is short, owing to the micron-size of the sorbent, while the presence of magnetic core allows readily separating these small sorbent particles.

The comparison of the statistical parameters (as reported in Table 1 , $\mathrm{R}^{2}$ and AIC) shows that the PFORE model (associated to the sorption rate) fits better the experimental profiles than the PSORE (which is frequently associated with the effect of resistance to intraparticle diffusion, according Hubbe et al., [42]), and the RIDE. However, the equilibrium times are relatively important (around 60-90 min), taking into account the micron-size of the sorbent (i.e., $\approx 20 \mu \mathrm{m}$ ) and the low values of the effective diffusivity coefficients mean that the resistance to intraparticle diffusion contributes to the control of kinetics, as a complement to the adsorption rate (PFORE).

\subsubsection{Sorption isotherms}

The sorption isotherms allow evaluating both the affinity of the sorbent for target solute and the maximum sorption capacity (at saturation, $\mathrm{q}_{\mathrm{m}}$ ). Practically, the maximum sorption capacity is rarely reached since this corresponds to high residual metal concentrations (which mean loss of high amounts of valuable or hazardous metal ions); however, this is useful for comparing different sorbents. On the other side, the affinity coefficient (assimilated to Langmuir constant, see Table $\mathrm{S} 1 \mathrm{~b})$ is correlated with the initial slope of the isotherm $\left(\mathrm{q}_{\mathrm{eq}}=\mathrm{f}\left(\mathrm{C}_{\mathrm{eq}}\right)\right)$; highly efficient sorbents offer steep initial slope (meaning reaching saturation for low residual concentration). Fig. 5 shows the comparison of isotherms for the three sorbents. While the functionalized sorbents show a tendency to form a saturation plateau, an exponential shape characterizes MC sorbent (in the range of concentration tested). The functionalized sorbents show remarkable reproducibility in the isotherm profiles with substantial improvement in sorption properties compared with the reference material (i.e., MC). This enhancement is measured by the increase of both maximum sorption capacity and initial slope according: MC «ATA@MC < AIC@MC; hence, qm values are 2.45 less than 5.43 less than $6.35 \mathrm{mmol} \mathrm{Cr} \mathrm{g}^{-1}$, respectively (Table 2). The Langmuir, Freundlich and Sips equations (Table S1b) were used for fitting the sorption isotherms. The solid lines show the Sips fit of sorption isotherms; fittings with alternative models are reported in Figure S11. Table 2 summarizes the parameters of the models for the different systems. The Langmuir equation corresponds to a mechanistic

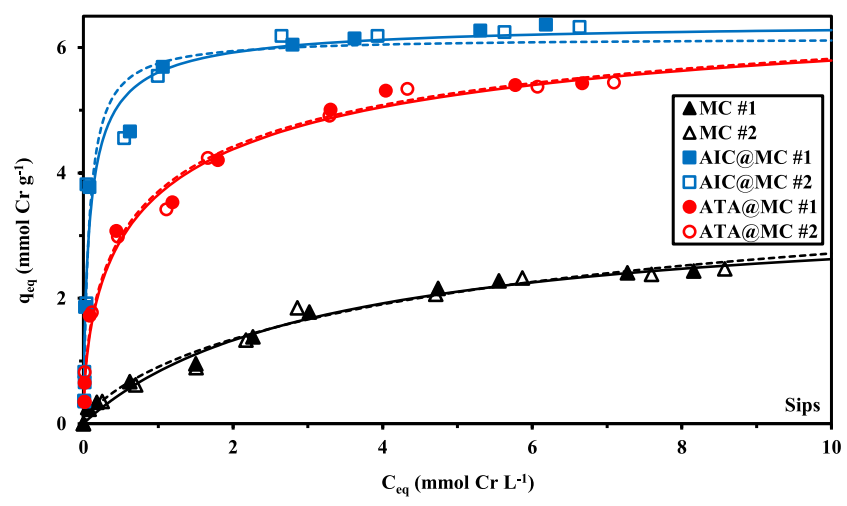

Fig. 5. $\mathrm{Cr}(\mathrm{VI})$ sorption isotherm MC, AIC@MC, and ATA@MC sorbents at $\mathrm{pH}_{0}$ 2 - Modeling with the Sips equation (SD: $0.5 \mathrm{~g} \mathrm{~L}^{-1}$; time: $48 \mathrm{~h}$; v: $210 \mathrm{rpm}$; T: 22 $\left.\pm 1{ }^{\circ} \mathrm{C}\right)$. 
Table 2

Modeling of $\mathrm{Cr}(\mathrm{VI})$ sorption isotherms for MC, AIC@MC, and ATA@MC sorbents at $\mathrm{pH}_{0} 2$.

\begin{tabular}{|c|c|c|c|c|c|c|c|c|}
\hline \multirow[t]{2}{*}{ Model } & \multicolumn{2}{|l|}{ Sorbent } & \multicolumn{2}{|l|}{ MC } & \multicolumn{2}{|c|}{ AIC@MC } & \multicolumn{2}{|c|}{ ATA@MC } \\
\hline & Parameter & Run \# & 1 & 2 & 1 & 2 & 1 & 2 \\
\hline Exper. & $\mathrm{q}_{\mathrm{m}, \exp .}$ & & 2.437 & 2.471 & 6.364 & 6.330 & 5.427 & 5.442 \\
\hline \multirow[t]{4}{*}{ Langmuir } & $\mathrm{q}_{\mathrm{m}, \mathrm{L}}$ & & 3.44 & 3.46 & 6.17 & 6.11 & 5.49 & 5.58 \\
\hline & $\mathrm{b}_{\mathrm{L}}$ & & 0.327 & 0.314 & 13.1 & 16.4 & 2.85 & 2.43 \\
\hline & $\mathrm{R}^{2}$ & & 0.988 & 0.985 & 0.972 & 0.947 & 0.974 & 0.977 \\
\hline & AIC & & -44 & -42 & -14 & -7 & -17 & -18 \\
\hline \multirow[t]{4}{*}{ Freundlich } & $\mathrm{k}_{\mathrm{F}}$ & & 0.932 & 0.894 & 4.59 & 4.63 & 3.36 & 3.32 \\
\hline & $\mathrm{n}_{\mathrm{F}}$ & & 2.04 & 1.99 & 4.39 & 4.71 & 3.42 & 3.45 \\
\hline & $\mathrm{R}^{2}$ & & 0.983 & 0.972 & 0.904 & 0.894 & 0.976 & 0.975 \\
\hline & AIC & & -42 & -36 & 0 & +1 & -19 & -19 \\
\hline \multirow[t]{5}{*}{ Sips } & $\mathrm{q}_{\mathrm{m}, \mathrm{s}}$ & & 4.75 & 3.5 & 6.15 & 6.43 & 7.41 & 7.34 \\
\hline & $\mathrm{b}_{\mathrm{S}}$ & & 0.236 & 0.309 & 14.0 & 6.74 & 1.00 & 0.991 \\
\hline & $\mathrm{n}_{\mathrm{S}}$ & & 1.33 & 1.02 & 0.993 & 1.29 & 1.77 & 1.73 \\
\hline & $\mathrm{R}^{2}$ & & 0.988 & 0.985 & 0.972 & 0.949 & 0.992 & 0.992 \\
\hline & AIC & & -42 & -38 & -10 & -3 & -27 & -29 \\
\hline
\end{tabular}

Units: $\mathrm{q}_{\mathrm{i}}: \mathrm{mmol} \mathrm{g}^{-1} ; \mathrm{b}_{\mathrm{i}}: \mathrm{L} \mathrm{mmol}^{-1} ; \mathrm{n}_{\mathrm{i}}$ : dimensionless; $\mathrm{k}_{\mathrm{F}}: \mathrm{L}^{1 / \mathrm{nF}} \mathrm{mmol}^{1-1 / \mathrm{nF}^{-1}} \mathrm{~g}^{-1}$.

model: the sorption is supposed to operate as a monolayer, with homogeneous distribution of sorption energies and without interaction between sorbed molecules. The Freundlich equation is a parametric mathematical equation corresponding to heterogeneous sorption with possible interactions between sorbed molecules; the model is missing physical significance (compared with the mechanistic Langmuir equation). The Sips equation is a combination of Langmuir and Freundlich equations. The incorporation of third-adjustable parameter makes easier the fit of experimental data with the 3-parameters equation, at the expense of a loss in physicochemical significance. The calculation of Akaike criterion (which takes into account the number of adjustable parameters) allows statistically comparing more accurately the quality of the fits. Generally, the preference for a model is attested by a difference in AIC values greater than 2 (in absolute values). For MC and AIC@MC, the Langmuir equation fits relatively better the isotherms than the other models; on the opposite hand, for ATA@MC, the Sips equation gives much lower values for AIC. Figure S11 Table 2 shows that the calculated values for the sorption capacities at saturation of the monolayer for the Langmuir equation are systematically higher than the experimental values for MC, but much closer for functionalized sorbents. The Sips model overestimates the saturation capacity for $\mathrm{MC}$ and ATA@MC (while for AIC@MC, the values are closer to the reality). Consistently with the slopes of the curves in Fig. 5, the affinity coefficients $\left(b_{\mathrm{L}}\right)$ follow the ranking: $\mathrm{MC}\left(0.32 \pm 0.07 \mathrm{~L} \mathrm{mmol}^{-1}\right)<$ ATA@MC $\left(2.64 \pm 0.21 \mathrm{~L} \mathrm{mmol}^{-1}\right)<$ AIC@MC $\left(14.8 \pm 1.7 \mathrm{~L} \mathrm{mmol}^{-1}\right)$.

It is noteworthy that the Langmuir isotherm supposes the surface to be homogeneous (sites and energy of sorption). The functionalization of the sorbent brings supplementary reactive groups, which may have different sorption energies. These heterogeneities may explain the divergences observed in the modeling of experimental profiles. The DualSite Langmuir (DSL) equation was precisely designed for taking into account the presence of heterogeneous reactive groups [44] (Eq. (2)):

$q_{e q}=\frac{q_{m, 1} C_{e q}}{1+b_{1} C_{e q}}+\frac{q_{m, 2} C_{e q}}{1+b_{2} C_{e q}}$

where $\mathrm{q}_{\mathrm{m}, \mathrm{i}}$ and $\mathrm{b}_{\mathrm{i}}$ are the maximum sorption capacity at saturation of the monolayer and the affinity coefficients for the two sites (i.e., $i=1$ or 2 ).

Figure S12 shows that the Dual-Site Langmuir model allows fitting better the experimental profiles in the region of greatest curvature. Table S10 summarizes the parameters for the Langmuir and the DualSite Langmuir equations and compares the statistical parameters. The improvement of the statistical fits (which must take into account the number of adjustable parameters, obviously increased for the DSL equation) is notably significant for ATA@MC; the conclusion is more debatable for AIC@MC. The maximum sorption capacities are more consistent for the Langmuir equation than for the dual-site model (where the maximum sorption is strongly overestimated; meaning that the reactive groups are not saturated under selected experimental conditions). In the case of AIC@MC, the second type of reactive groups is characterized by much lower sorption capacity and affinity coefficient: the first type of reactive groups is the major contributor to chromate binding. On the opposite hand, for ATA@MC the first reactive have lower sorption capacity and higher affinity contrary to second reactive group, which is characterized by lower affinity and higher capacity. It is noteworthy that the calculated parameters for the DSL are less consistent in terms of reproducibility (higher dispersion) than using the Langmuir equation.

The higher sorption capacity and stronger affinity of AIC@MC compared with ATA@MC may be associated with different criteria; including the density of reactive groups (Table S2), their proper reactivity (hard and soft acid base principles), and surface charge characteristics (in relation to acid/base properties, Figure S8). Chromate ions are classified as hard acids according to Pearson's rules [45]. On the other hand, functionalized sorbents are multi-functional, while bearing imidazole, amide and amine groups for AIC@MC; ATA@MC holds thiazole, carboxylate and amine groups. Andersson Trojer et al., [46] compared the antifouling properties of imidazole and thiazole functionalized compounds (through their affinity with copper): they identified the different reactive groups as potential nitrogen coordinating borderline ligands (imidazole, triazole), hard ligands (amine), oxygen coordinating hard ligands (such as carboxylic groups), and sulfur coordinating soft ligands. These coordinating properties are supposed to be more active for intermediary $\mathrm{pH}$ values (closer to neutrality) while the sorption at $\mathrm{pH} 2$ is expected to proceed preferentially through electrostatic attraction/ion exchange. The density of amine groups (primary, secondary and tertiary), which are hard ligands, is stronger for AIC@MC than for ATA@MC. Whatever, the mechanism of interaction (ion exchange vs. chelation), the higher density of amine groups in AIC@MC may explain its stronger efficiency for chromate sorption compared with ATA@MC. In the case of MC, chromate removal proceeds through interactions with protonated amine groups by electrostatic attraction/ion exchange.

Obviously, the possible occurrence of complementary reduction reactions makes more complex the interpretation of sorption mechanisms and the assignment of the enhancement of sorption performance to specific reactive groups.

Table S11 compares the sorption performance of the new sorbents with data reported in the literature for both biosorbents and synthetic materials. Magnetic chitosan (MC) shows comparable sorption properties than amine-functionalized silica/magnetite composite [47]. ATA@MC gives sorption levels comparable to ionic liquid-impregnated metal organic framework [48], although with faster kinetics. However, AIC@MC shows outstanding sorption performances surpassing those of 
alternate sorbents. This comparison demonstrates the promising performances of these functionalized sorbents for the removal of chromate ions. This potential must be confirmed by the investigation of selectivity and recycling possibilities (see below).

\subsubsection{Sorption selectivity - multi-component solutions}

The sorption of chromate in the presence of equimolar concentrations $\left(\sim 1 \mathrm{mmol} \mathrm{L}^{-1}\right)$ of other metal ions such as $\mathrm{Ca}(\mathrm{II}), \mathrm{Cu}(\mathrm{II}), \mathrm{Cd}(\mathrm{II}), \mathrm{Ni}$ (II), and $\mathrm{Zn}$ (II) at three $\mathrm{pH}_{0}$ values $(2,4$, and 5) is summarized in Figure S13. Chromium sorption capacities for both AIC@MC and ATA@MC decrease with increasing pH (consistently with results from mono-component solutions), while a reciprocal trend is observed for competitor metal ions. This is directly correlated with the different modes of interactions of the reactive groups for metal anions (electrostatic attraction/ion-exchange for chromate) and metal cations (chelation for metal cations). At moderately acidic $\mathrm{pH}$ values, the sorption of chromate anions (electrostatic attraction on protonated groups or anionexchange) is favored while the chelation of metal cations requires the deprotonation of functional groups for efficient binding. The cumulative sorption capacities reach a maximum at $\mathrm{pH}_{0} 4: 3.17 \mathrm{mmol} \mathrm{g}^{-1}$ and 3.56 mmol g ${ }^{-1}$ for AIC@MC and ATA@MC, respectively. It is noteworthy that ATA@MC shows higher sorption capacity for multi-metals than AIC@MC, contrary to the specific data obtained with $\mathrm{Cr}(\mathrm{VI})$ alone.

Under the most favorable conditions for alternative metal ions (i.e., $\mathrm{pH}_{\mathrm{eq}} 4.55-4.51$ ), the sorption capacities remain below $0.85 \mathrm{mmol} \mathrm{g}^{-1}$ for $\mathrm{Zn}(\mathrm{II})$ (which has the highest affinity from this group). This is far below the sorption capacity obtained from chromate anions at $\mathrm{pH}_{\mathrm{eq}}$ $2.27-2.21$; i.e., $1.84-171 \mathrm{mmol} \mathrm{Cr} \mathrm{g}^{-1}$. The two sorbents show similar order of preference at $\mathrm{pH}_{0} 5$ :

$\mathrm{Zn}(I I)>>\mathrm{Ni}(\mathrm{II})>\mathrm{Cu}(\mathrm{II})>>\mathrm{Cd}(\mathrm{II})>\mathrm{Ca}(\mathrm{II})$.

$\mathrm{Ca}(\mathrm{II})$ and $\mathrm{Cd}(\mathrm{II})$, which have the lowest affinity for the two sorbents, are characterized by the highest ionic radii (i.e., $1.12 \AA$ and $0.95 \AA$, respectively), significantly larger than the values for $\mathrm{Zn}(\mathrm{II}), \mathrm{Ni}(\mathrm{II})$ and $\mathrm{Cu}$ (II) (in the range 0.69-0.74 $\mathrm{A}$ ) [49]. It is noteworthy that $\mathrm{Ca}$ (II) is part of hard acid according Pearson's rules [45], contrary to Cd(II), which is ranked among soft acids. Hard acids have marked preference for $\mathrm{N}$ - and O-bearing ligands while soft acids readily react with S-bearing ligands. The preference order of the sorbents for the three other metal cations (which are considered borderline acids) follow other criteria ranking such as the $\chi_{\mathrm{aq}}$ (i.e., the solution-phase electronegativity, [50]) and the enthalpy change of hydration (Table S12). The affinity of the sorbents for selected metal cations can be also confronted to their speciation under experimental conditions of the multi-component tests (Table S13). At $\mathrm{pH}_{0} 5, \mathrm{Ca}$ (II) is mainly present as $\mathrm{CaCl}^{+}(\sim 94.8 \%)$, and $\mathrm{Cd}(\mathrm{II})$ as free $\mathrm{Cd}^{2+}(\sim 61.9 \%)$ and $\mathrm{CdCl}^{+}(\sim 35.0 \%)$. On the opposite hand, the metal cations that have higher affinity for the sorbents are largely predominant as free species (i.e., 95.6-97.2\%). The ability of the ligands to bind free species seems to be another important parameter for controlling the binding of metal cations, in addition to the other criteria of hydrated ionic radius and solution-phase electronegativity.

The selectivity coefficient $\left(\mathrm{SC}_{\mathrm{Cr} / \mathrm{Metal}}\right)$ is defined as the ratio of distribution ratios:

$\mathrm{SC}_{\mathrm{Cr} / \text { Metal }}=\frac{\mathrm{D}_{\mathrm{Cr}}}{\mathrm{D}_{\text {Metal }}}=\frac{\mathrm{q}_{\mathrm{eq}(\mathrm{Cr})} \times \mathrm{C}_{\mathrm{eq}(\text { Metal })}}{\mathrm{C}_{\mathrm{eq}(\mathrm{Cr})} \times \mathrm{q}_{\mathrm{eq}(\text { Metal })}}$

Fig. 6 compares the SC values for the different metal cations against chromate sorption at different $\mathrm{pH}$ values. At $\mathrm{pH} 2$, the sorbents show remarkable selectivity for $\mathrm{Cr}(\mathrm{VI})$ : in the range 65.6-182.7 for AIC@MC and 35.6-88.4 for ATA@MC. These values confirm that AIC@MC is more selective for $\mathrm{Cr}(\mathrm{VI})$ against heavy metal cations than ATA@MC. These trends are correlated with the values of $\mathrm{pH}_{\mathrm{PZC}}$ : AIC@MC $\left(\mathrm{pH}_{\mathrm{PZC}}\right.$ : $5.66)$ is more protonated at $\mathrm{pH} 4-5$ than ATA@MC ( $\mathrm{pH}_{\mathrm{PZC}}$ : 5.66). For mild acidic conditions $\left(\mathrm{pH}_{0}: 5\right)$, the sorbents are not selective: the $\mathrm{SC}_{\mathrm{Cr}}$ / Metal varies in the ranges: $0.23-0.80$ for AIC@MC and 0.34-0.95 for
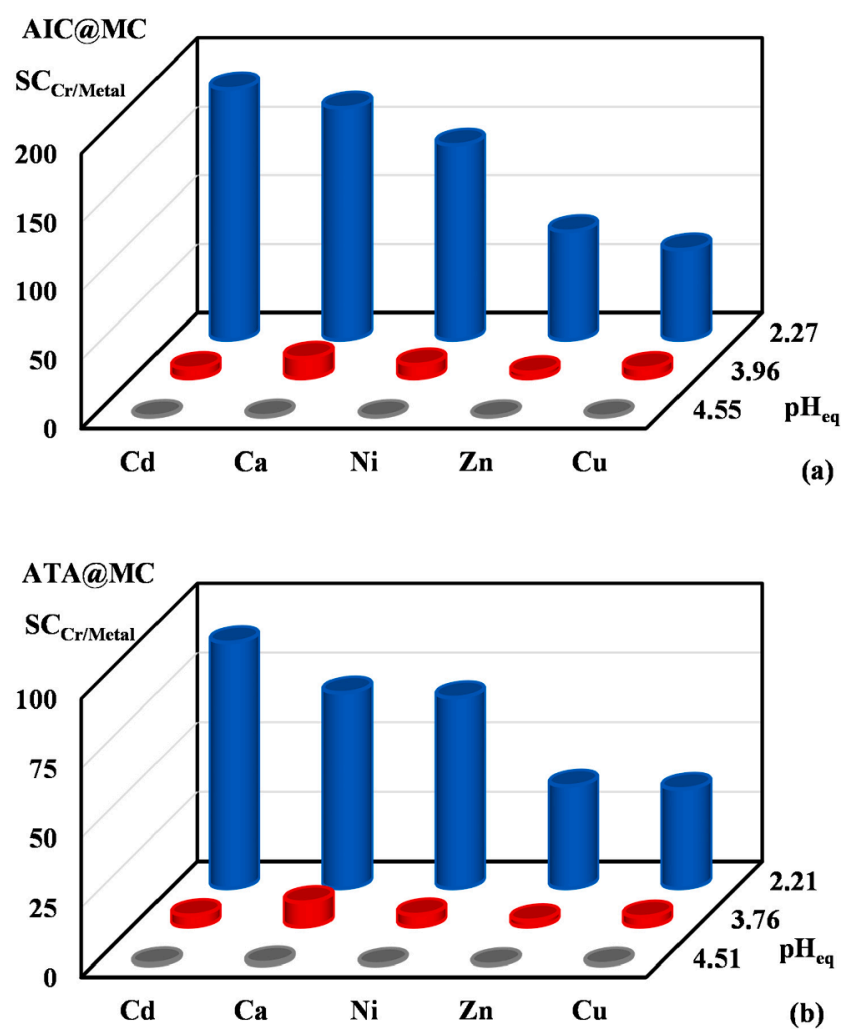

Fig. 6. Effect of $\mathrm{pH}_{\mathrm{eq}}$ on the selectivity coefficient of AIC@MC and ATA@MC for $\mathrm{Cr}(\mathrm{VI})$ uptake against $\mathrm{Cd}(\mathrm{II}), \mathrm{Ca}(\mathrm{II}), \mathrm{Ni}(\mathrm{II}), \mathrm{Zn}(\mathrm{II})$, and $\mathrm{Cu}(\mathrm{II})$ (equimolar 1 mmol L ${ }^{-1}$ solutions; SD: $0.5 \mathrm{~g} \mathrm{~L}^{-1}$; T: $22 \pm 1{ }^{\circ} \mathrm{C}$; v: $210 \mathrm{rpm}$; contact time: $5 \mathrm{~h}$ ).

\section{ATA@MC.}

\subsubsection{Metal desorption and sorbent recycling}

Metal desorption and sorbent recycling are critical parameters for the evaluation of the sorbents. The selection of $\mathrm{pH}$ for chromate sorption showed the sensitivity of the process to the competition effect of the counter anions released by acids. This is a first indication that acidic solutions can be efficient for reversing the binding of chromate anions from loaded sorbents. On the other side, the presence of magnetite in the composite sorbents means that the magnetic core may be sensitive to excessive acidity (due to nanoparticle dissolving if exposed to very low$\mathrm{pH}$ solutions). Previous tests on magnetite stability into magneticchitosan based sorbents have shown that in $0.5 \mathrm{M} \mathrm{HCl}$ solutions, the loss in iron after $24 \mathrm{~h}$ of contact does not exceed $1.1 \%$ (referred to the amount of magnetite into the composite) [51]. In addition, the FTIR characterization and the semi-quantitative EDX analysis showed that cross-linked materials are highly stable under selected conditions for sorption and desorption cycles. A good compromise may consist of using $\mathrm{HCl}$ solutions of mild concentration; herein, $0.5 \mathrm{M} \mathrm{HCl}$ solutions were used. Figure S14 compares the kinetic profiles for desorption of chromate from metal loaded sorbents. The profiles of desorption are superposed for functionalized sorbents (duplicate tests confirm the reproducibility of the experiments). Raw MC sorbent shows little faster chromate desorption than functionalized materials. A contact time of 25 min is sufficient to achieve the complete elution of chromate. This means that chromate desorption is a little faster than the sorption step. Short contact times also contributes to the stability of magnetite core in the composite when exposed to $0.5 \mathrm{M} \mathrm{HCl}$ eluent.

The two sorbents show remarkable stability in both sorption and desorption performances for at least five cycles (Table 3). Chromate is fully desorbed using $0.5 \mathrm{M} \mathrm{HCl}$ solutions. At the fifth cycle, the sorption efficiency decreases by less than $6 \%$ compared with the sorption reported at the first use of the sorbents. Despite the chemical changes 
Table 3

Recycling of AIC@MC and ATA@MC sorbents - Sorption (SE) and desorption (DE) efficiencies for five successive cycles.

\begin{tabular}{|c|c|c|c|c|c|c|c|c|}
\hline \multirow[t]{3}{*}{ Cycle } & \multicolumn{4}{|c|}{ AIC@MC } & \multicolumn{4}{|c|}{ ATA@MC } \\
\hline & \multicolumn{2}{|c|}{$\begin{array}{l}\text { Sorption } \\
\text { efficiency (\%) }\end{array}$} & \multicolumn{2}{|c|}{$\begin{array}{l}\text { Desorption } \\
\text { efficiency (\%) }\end{array}$} & \multicolumn{2}{|c|}{$\begin{array}{l}\text { Sorption } \\
\text { efficiency (\%) }\end{array}$} & \multicolumn{2}{|c|}{$\begin{array}{l}\text { Desorption } \\
\text { efficiency (\%) }\end{array}$} \\
\hline & Aver. & $\begin{array}{l}\text { St. } \\
\text { Dev. }\end{array}$ & Aver. & $\begin{array}{l}\text { St. } \\
\text { Dev. }\end{array}$ & Aver. & $\begin{array}{l}\text { St. } \\
\text { Dev. }\end{array}$ & Aver. & $\begin{array}{l}\text { St. } \\
\text { Dev. }\end{array}$ \\
\hline 1 & 91.8 & 0.5 & 100.1 & 0.0 & 76.9 & 0.8 & 99.9 & 0.0 \\
\hline 2 & 90.7 & 0.3 & 99.9 & 0.1 & 76.4 & 0.9 & 100.0 & 0.1 \\
\hline 3 & 89.2 & 0.1 & 100.1 & 0.0 & 75.8 & 1.5 & 100.3 & 0.4 \\
\hline 4 & 88.1 & 0.2 & 100.0 & 0.0 & 74.4 & 1.0 & 100.0 & 0.0 \\
\hline 5 & 86.7 & 0.0 & 100.0 & 0.1 & 73.0 & 1.8 & 99.9 & 0.2 \\
\hline $\begin{array}{c}\Delta\left(5^{\mathrm{th}} /\right. \\
\left.1^{\text {st }}\right)\end{array}$ & -5.6 & & $\sim$ & & -5.1 & & $\sim$ & \\
\hline
\end{tabular}

observed on the FTIR spectra of the sorbents after five cycles of sorption and desorption (Fig. 1 and Tables S4a and S4b), which are probably associated to the weak degradation of the sorbents (through oxidation of some reactive groups), they remain very efficient for chromate uptake.

\subsection{Treatment of tannery wastewater}

The tannery wastewater is characterized by huge concentrations of metal contaminants (Table 4). Chromate concentration reaches up to $217.2 \mathrm{mmol} \mathrm{Cr} \mathrm{L}^{-1}$ (i.e., $11.3 \mathrm{~g} \mathrm{Cr} \mathrm{L}^{-1}$ ); much higher than other metal ions (in the range: $0.22-1.34 \mathrm{mmol} \mathrm{L}^{-1}$ for $\mathrm{Cd}(\mathrm{II}), \mathrm{Pb}(\mathrm{II}), \mathrm{Co}(\mathrm{II})$, and $\mathrm{Ni}(\mathrm{II})$, or $32-79 \mathrm{mg} \mathrm{L}^{-1}$ ); chromate is in large excess, from 163 times for Co(II) up to 961 times for $\mathrm{Pb}(\mathrm{II})$. Obviously, this level of concentration for chromate is too high for making the sorption process competitive; sorption processes make usually sense for concentration below $100-200 \mathrm{mg} \mathrm{L}^{-1}$. However, this type of complex effluent is interesting for evaluating the potential of these sorbents. Figure S15 and S16 compare the recovery efficiencies (R\%) and selectivity coefficients of AIC@MC and ATA@M, respectively, for different sorbent doses (in the range 1-30 $\mathrm{g} \mathrm{L}^{-1}$ ), for selected metal ions at $\mathrm{pH}_{0} 2$ and 5 .

As expected, at $\mathrm{pH}_{0} 2$, chromate anions are most efficiently removed than other metal cations: the maximum sorption of cations does not exceed 38.3\% for AIC@MC and 64\% for ATA@MC (which is less selective as seen above). Obviously, increasing the sorbent dose increases the efficiency, up to $99 \%$ for $\mathrm{Cr}(\mathrm{VI})$ at SD: $30 \mathrm{~g} \mathrm{~L}^{-1}$. The selectivity coefficients give indicative trends; indeed, the fact that chromate concentration is in large excess against those of other metals introduces a bias in the comparison. Consistently with previous conclusions, the SC values for AIC@MC (in the range 380-503) are considerably higher than those of ATA@MC are (in the range 89-198). The selectivity orders are:

$C d(I I)>N i(I I)>C o(I I)>P b(I I)$ for $A I C @ M C$,

$\mathrm{Ni}(I I)>\mathrm{Pb}(I I)>\mathrm{Co}(I I)>C d(I I)$ for ATA $@ M C$

The inversion in the selectivity for chromate against Cd(II) between AIC@MC and ATA@MC may be associated with the presence of S- bearing functional groups (soft base), which have a greater affinity for soft acids (like Cd(II)). S-donor groups contribute more to the binding of $\mathrm{Cd}(\mathrm{II})$, which, in turn, reduces the global selectivity of the sorbent for $\mathrm{Cr}$ (VI).

At $\mathrm{pH}$ 5, the two sorbents show a wider reactivity for heavy metal cations (contrary to chromate sorption efficiency that decreases). This is especially true in the case of ATA@MC. At the highest sorbent dose (i.e., $30 \mathrm{~g} \mathrm{~L}^{-1}$ ), for AIC@MC, the maximum removals are obtained for Cd(II), $\mathrm{Pb}$ (II) and $\mathrm{Ni}(\mathrm{II})$; the sorption efficiencies do not exceed $86.2 \%, 75.4 \%$, and $66.2 \%$, respectively (only $49 \%$ for chromate). For ATA@MC, metal removals yield $97.7 \%, 90.6 \%, 61.1 \%$, and $51.5 \%$ for $\mathrm{Pb}(\mathrm{II}), \mathrm{Cd}(\mathrm{II})$, Co (II) and $\mathrm{Ni}(\mathrm{II})$, respectively (less than $42 \%$ for chromate). This broader reactivity of the sorbents directly influences their selectivity for $\mathrm{Cr}(\mathrm{VI})$ against heavy metal cations (Figure S15). For AIC@MC, the selectivity the most notable is observed at low SD for $\mathrm{Co}(\mathrm{II})$ (close to 15) $>\mathrm{Pb}$ (II) $\mathrm{Ni}(\mathrm{II})$. As expected, in the case of ATA@MC, the selectivity coefficients for $\mathrm{Cr}(\mathrm{VI})$ decrease down to 4 against $\mathrm{Ni}(\mathrm{II})$ and lower than 2 against all over metal ions. The selectivity decreases with increasing the $\mathrm{pH}$ and with the presence of S-bearing functional groups.

Table S9 reported the distribution of the different metals (semiquantitative EDX analysis) at the surface of sorbent particles after being exposed to tannery wastewater (at different $\mathrm{pH}$ values; i.e., 2 and 5).

Table 4 summarizes the optimum conditions and performance (at the highest SD) for the different systems (metal/pH). AIC@MC is definitively the most efficient and the most selective for chromate recovery at pH 2 (sorption efficiency reaches $99.6 \%$, less than $39 \%$ for other metal cations, despite much lower concentrations). At this pH, ATA@MC is less selective but reaches good removal efficiency for $\mathrm{Cr}(\mathrm{VI}$ ) (of the same order of magnitude as AIC@MC) and Co(II) (at 60.9\%). For the treatment at pH 5, ATA@MC is more efficient for the binding of heavy metals: the sorption efficiency reaches up to $97.7 \%$ for $\mathrm{Pb}(\mathrm{II}), 90.6 \%$ for $\mathrm{Cd}(\mathrm{II})$. For $\mathrm{Co}(\mathrm{II})$ and $\mathrm{Ni}(\mathrm{II})$, lower removal yields are reported in the range $40-66 \%$. Table S14 offers another view on these experimental optimized conditions; this table compares the levels reached after treatment with the regulations for water use in drinking water, irrigation and livestock drinking water. Obviously, the complexity of the solution and the high levels of metal concentrations do not allow reaching the standards for direct utilization of treated effluents for irrigation, animal and human uses. However, these tests clearly demonstrate the robustness and efficiency of AIC@MC (and ATA@MC to a lesser extent) for the selective recovery of chromate anions in acidic solutions.

\subsection{Evaluation of antimicrobial activities}

The parallel tests on DMSO (blank control) show that the polar aprotic solvent does not show any antimicrobial activity (Figure S17): it was not possible to detect any zone of exclusion around the well when DMSO was dropped into. Figure S17 also shows some examples of the Petri-dishes for the five microorganisms at different doses of the antimicrobial agents. The plot of the ZOI values for the different systems confirms that the antimicrobial activity depends on the dose, the

Table 4

Sorption efficiencies and residual metal concentrations for the treatment of tannery wastewater (SD: $30 \mathrm{~g} \mathrm{~L}^{-1}$ ) using AIC@MC and ATA@MC at pH 2 and 5.

\begin{tabular}{|c|c|c|c|c|c|c|c|c|c|}
\hline \multirow[t]{3}{*}{ Metal } & \multirow{3}{*}{$\frac{\mathrm{pH}_{0}}{\frac{\text { Sorbent }}{\mathrm{C}_{0}}}$} & \multicolumn{4}{|l|}{2} & \multicolumn{4}{|l|}{5} \\
\hline & & \multicolumn{2}{|c|}{ AIC@MC } & \multicolumn{2}{|c|}{ ATA@MC } & \multicolumn{2}{|c|}{ AIC@MC } & \multicolumn{2}{|c|}{ ATA@MC } \\
\hline & & $\mathrm{C}_{\mathrm{eq}}$ & SE (\%) & $\mathrm{C}_{\mathrm{eq}}$ & SE (\%) & $\mathrm{C}_{\mathrm{eq}}$ & SE (\%) & $\mathrm{C}_{\mathrm{eq}}$ & SE (\%) \\
\hline $\mathrm{Cr}$ & 217 & 0.917 & 99.6 & 1.37 & 99.4 & 110 & 49.2 & 127 & 41.3 \\
\hline $\mathrm{Cd}$ & 0.423 & 0.288 & 31.9 & 0.153 & 63.9 & 0.059 & 86.2 & 0.040 & 90.6 \\
\hline $\mathrm{Pb}$ & 0.226 & 0.139 & 38.3 & 0.096 & 57.5 & 0.055 & 75.4 & 0.005 & 97.7 \\
\hline Co & 1.34 & 0.877 & 34.4 & 0.522 & 60.9 & 0.792 & 40.8 & 0.52 & 61.1 \\
\hline \multirow[t]{3}{*}{$\mathrm{Ni}$} & 0.547 & 0.366 & 33.2 & 0.304 & 44.4 & 0.185 & 66.2 & 0.266 & 51.5 \\
\hline & $\mathrm{pH}_{\mathrm{eq}}$ & 2.16 & & 2.27 & & & & & \\
\hline & & & & & & 5.19 & & 5.23 & \\
\hline
\end{tabular}

Bold: individual optimal conditions for metal removal; Units: $\mathrm{C}$ values in mmol $\mathrm{L}^{-1}$. 
microorganism, and the composite (Fig. 7).

Hence, at the lowest concentration (i.e., $50 \mu \mathrm{g} \mathrm{mL}^{-1}$ ), the three materials have comparable ZOI values for E.coli (i.e., $9.3 \pm 0.5 \mathrm{~mm}$ ) and C. albicans (i.e., $9.1 \pm 0.6 \mathrm{~mm}$ ). It is noteworthy that for $P$. aeruginosa, $B$. subtilis and $S$. aureus none of the materials show any antimicrobial activity; meaning that the MIC (minimum inhibitory concentration) value is higher than $50 \mu \mathrm{gL}^{-1}$ (Figure 9). On the opposite hand, for the concentration of $25 \mu \mathrm{g} \mathrm{mL}{ }^{-1}$, none of the materials forms an exclusion zone around the wells, regardless of the microorganism. Therefore, the MIC is close to $50 \mu \mathrm{g} \mathrm{mL}^{-1}$ for E. coli and C. albicans.

When increasing the dose to $100 \mu \mathrm{gL}^{-1}$, the ZOI values slightly increase in the range $9-12 \mathrm{~mm}$. The highest antimicrobial activity is observed for $P$. aeruginosa with ZOI: $11.7 \pm 0.5$ for both AIC@MC and ATA@MC, while for MC, the effect is slightly reduced (i.e., ZOI: $9.7 \pm$ 0.5 ). These differences are statistically significant (at $p$ less than 0.05 ). For the other systems, the differences are not marked enough to differentiate the materials.

At the highest dose (i.e., $200 \mu \mathrm{g} \mathrm{m}^{-1}$ ), the antimicrobial responses of AIC@MC and ATA@MC are comparable with average ZOI values of 11.7-12.7 $\mathrm{mm}$ for $B$. subtilis and $S$. aureus, $15.3-16.3 \mathrm{~mm}$ for P. aeruginosa, $12.7-13 \mathrm{~mm}$ for E. coli, and $12.3-13.7 \mathrm{~mm}$ for C. albicans. These differences between the two materials are not significant. On the opposite hand, the ZOI values are significantly lower for MC (especially for $P$. aeruginosa, E. coli, and C. albicans; i.e., ZOI: $10.7-11.7 \mathrm{~mm}$ ). Pseudomonas aeruginosa is clearly more sensitive to functionalized MC than the other microorganisms.

The analysis of data shows that the MIC value for MC, AIC@MC, and ATA@MC is around $100 \mu \mathrm{mL}^{-1}$ for B. subtilis, S. aureus, and $P$. aeruginos $a$ with ZOIs ranging between $9.3 \pm 0.6 \mathrm{~mm}$ and $11.7 \pm 0.6$ $\mathrm{mm}$. The MIC value for tested composites against $E$. coli and $C$. albicans was $50 \mu \mathrm{g} \mathrm{mL}^{-1}$ with ZOI values of $8.6-9.3 \mathrm{~mm}$ (ZOI: $10.0-11.7 \mathrm{~mm}$ at $100 \mu \mathrm{g} \mathrm{mL}^{-1}$ ).

Generally, these data suggest that functionalized magnetic chitosan materials are slightly more effective than raw magnetite/chitosan micro-particles and that the $\mathrm{Gram}^{-}$bacteria are more sensitive to $\mathrm{Gram}^{+}$ bacteria. Unicellular fungi (C. albicans) shows a sensitivity to antimicrobial functionalized composites that is globally intermediary between the responses of $P$. aeruginosa and $E$. coli.

This differential activity is consistent with the results reported by Hamza et al., [52]: phosphorylated guar gum/magnetic chitosan composite revealed having a higher antimicrobial activity for $\mathrm{Gram}^{-}$than for $\mathrm{Gram}^{+}$bacteria. Carboxymethyl chitosan tends to inhibit the formation of Gram ${ }^{-}$bacteria (lower effect on $\mathrm{Gram}^{+}$bacteria) [53]. This difference in sensitivity is frequently associated with differences in the constituents of the cell wall of the microorganisms. Whereas $\mathrm{Gram}^{+}$bacteria hold peptidoglycan layers, the outer membrane of $\mathrm{Gram}^{-}$bacteria is characterized by the presence of lipopolysaccharides (outer part) associated with a phospholipid layer (inner part). This inhibitory effect may be explained by the interaction between negatively-charged lipopolysaccharides and positively-charged NPs $[54,55]$. In addition, the antimicrobial effect of magnetite/chitosan nanoparticles benefits of the synergistic effect of the magnetite nanoparticles and chitosan-based layer, as reported by Li et al. [56], in the case of the inhibition of Xanthomonas oryzae by chitosan/ $/ \mathrm{TiO}_{2} \mathrm{NPs}$. The positive impact of nanoparticles on the protection against fungi was reported in the case of Fusarium graminearum (responsible for wheat head blight) [57]: the nanoparticles enhance the growth of the microorganisms and the formation of macroconidia. Several interpretations have been proposed for explaining the effect of metal nanoparticles and nanomaterials: (a) transfer of metal ions into the cells, (b) production of reactive oxygen species (ROS), and (c) disruption of cell membrane, which affects its selective permeability $[58,59]$. ROS are well known for their destructive impact on nucleic acid, lipids, proteins, amino acids, and phospholipids [54]. The accumulation of metal and metal oxides NPs inside the cell leads to a change in the proton motive force, which alters the selective permeability and hence discharges the cellular components out of the cell $[60,61]$. The release of metal ions (herein $\mathrm{Fe}^{2+}$ ) has a negative impact on enzymatic reaction, cellular metabolism; alternative effects concern the hindrance of active transport, and its combination with macromolecules leading to microbial death $[62,63]$.

\section{Conclusion}

Functionalized sorbents show outstanding sorption properties for $\mathrm{Cr}$ (VI) removal from acidic aqueous solutions (i.e., at $\mathrm{pH} 2$ ). The FTIR and XPS characterizations demonstrate that the removal of chromate involves $\mathrm{O}$ - and N-bearing groups present in the solution through electrostatic attraction/ion exchange mechanisms (chromate anions being bound to protonated amine groups). The reduction of $\mathrm{Cr}(\mathrm{VI})$ into $\mathrm{Cr}(\mathrm{III})$ is also demonstrated by XPS analysis. This dual mechanism makes difficult the interpretation of effective removal mechanisms (and more specifically to quantify the relative contributions of the two mechanisms). Uptake kinetics are fast and fitted by the pseudo-first order rate equation; however, the contribution of resistance to intraparticle diffusion cannot be neglected. Maximum sorption capacities reach up to $6.35 \mathrm{mmol} \mathrm{Cr} \mathrm{g}^{-1}$ (for AIC@MC) and $5.43 \mathrm{mmol} \mathrm{Cr} \mathrm{g}^{-1}$ (for ATA@MC). The Langmuir and the Sips equations fit the sorption isotherms. The Dual-Site Langmuir equation improves the quality of the Langmuir fit, taking into account sorbent heterogenity. The selectivity of the sorbents for $\mathrm{Cr}(\mathrm{VI})$ over heavy metals such as $\mathrm{Ca}(\mathrm{II}), \mathrm{Cu}(\mathrm{II}), \mathrm{Cd}(\mathrm{II}), \mathrm{Ni}(\mathrm{II})$ and $\mathrm{Zn}$ (II)) increases with decreasing the pH; AIC@MC being more selective than ATA@MC. Chromate desorption is highly efficient and fast, while using $0.5 \mathrm{M} \mathrm{HCl}$ solutions. The recycling shows remarkable stability in terms of both sorption and desorption performances. In complex solutions (tannery wastewater) AIC@MC is more selective (against other metal cations) while ATA@MC has a wider range of activity against Cd

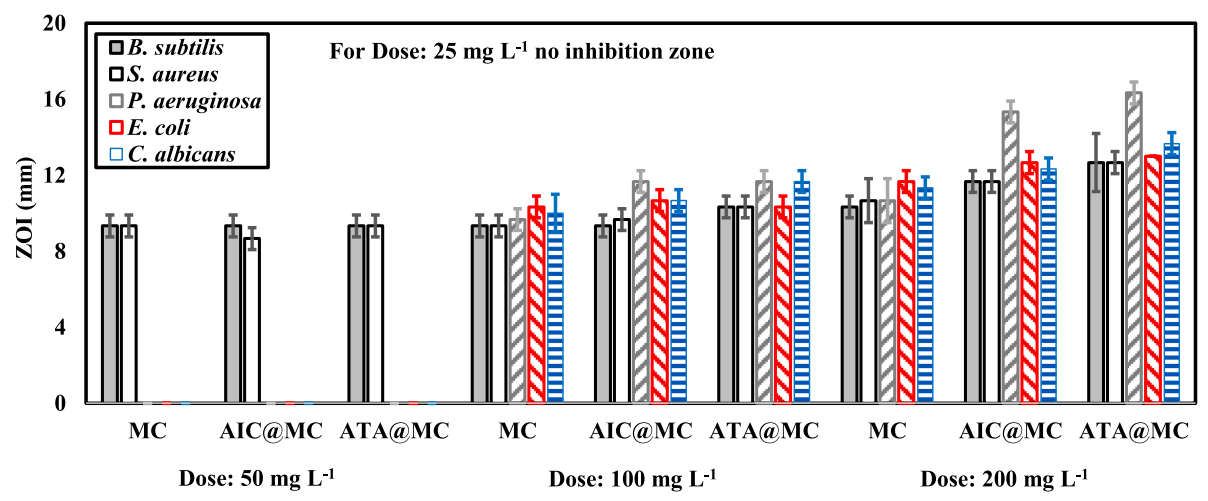

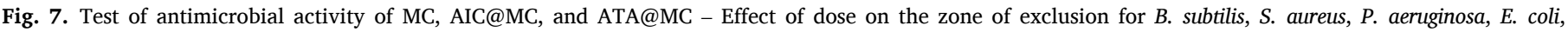
and C. albicans. 
(II), $\mathrm{Pb}(\mathrm{II}), \mathrm{Co}(\mathrm{II})$, and $\mathrm{Ni}(\mathrm{II})$ (especially at $\mathrm{pH}$ 5).

The functionalization of MC microparticles slightly increases the antimicrobial activity, which is a little better against $P$. aeruginosa, compared with B. subtilis, S. aureus), E. coli bacteria, and pathogenic yeast (C. albicans).

\section{Declaration of Competing Interest}

The authors declare that they have no known competing financial interests or personal relationships that could have appeared to influence the work reported in this paper.

\section{Acknowledgements}

Y. W. thanks the support of NSFC (National Natural Science Foundation of China) Projects (No. 11975082, U1967218). E.G., A. A-H.A. and M.F.H., acknowledge the cooperation joint through the IMHOTEP project "MetalValor" (ref. 39529QA) from Institut Francais d'Egypte and Egyptian Academy of Science and Technology.

\section{Appendix A. Supplementary data}

Supplementary data to this article can be found online at https://doi. org/10.1016/j.cej.2021.131775.

\section{References}

[1] A.M. Cardinale, C. Carbone, S. Consani, M. Fortunato, N. Parodi, Layered double hydroxides for remediation of industrial wastewater from a galvanic plant, Crystals, 10, 2020, Art. $\mathrm{N}^{\circ} 10060443$.

[2] P. Singh, N. Itankar, Y. Patil, Biomanagement of hexavalent chromium: Current trends and promising perspectives, J. Environ. Manage., 279 (2021) Art. $\mathrm{N}^{\circ}$ 111547.

[3] X. Tang, H. Wu, X. Quan, C. Feng, G. Li, F. Qiu, Separation of sodium chromate from high alkaline media based on precipitation transformation using barium hydroxide, New J. Chem. 44 (2020) 12048-12057.

[4] G.P. Gallios, M. Vaclavikova, Removal of chromium (VI) from water streams: a thermodynamic study, Environ. Chem. Lett. 6 (4) (2008) 235-240.

[5] F. Yao, M. Jia, Q. Yang, K. Luo, F. Chen, Y. Zhong, L. He, Z. Pi, K. Hou, D. Wang, et al., Electrochemical $\mathrm{Cr}(\mathrm{VI})$ removal from aqueous media using titanium as anode: Simultaneous indirect electrochemical reduction of $\mathrm{Cr}(\mathrm{VI})$ and in-situ precipitation of Cr(III), Chemosphere, 260 (2020) Art. $\mathrm{N}^{\circ} 127537$.

[6] V. Kumar, S.K. Dwivedi, Hexavalent chromium reduction ability and bioremediation potential of Aspergillus flavus CR500 isolated from electroplating wastewater, Chemosphere, 237 (2019) Art. $\mathrm{N}^{\circ} 124567$.

[7] A. Senol, Extractive removal of Cr(VI) from aqueous acidic media by aliquat 336/ xylene system: optimization and modelling of equilibrium, Indian J. Chem. Technol. 24 (2017) 269-283.

[8] D.V. Morales, O. Kusku, B.L. Rivas, M. Arda, N. Kabay, M. Bryjak, Removal of Cr (VI) by stabilized solvent impregnated resin (SIR) prepared by using a hydrophilic polymer adsorbent and Aliquat 336, J. Chil. Chem. Soc. 64 (2019) 4432-4436.

[9] R. Güell, E. Antico, V. Salvado, C. Fontas, Efficient hollow fiber supported liquid membrane system for the removal and preconcentration of $\mathrm{Cr}(\mathrm{VI})$ at trace levels, Sep. Purif. Technol. 62 (2008) 389-393.

[10] Y. Hu, G. Zhan, X. Peng, X. Liu, Z. Ai, F. Jia, S. Cao, F. Quan, W. Shen, L. Zhang, Enhanced $\mathrm{Cr}(\mathrm{VI})$ removal of zero-valent iron with high proton conductive FeC2O4.2H2O shell, Chem. Eng. J., 389 (2020) Art. N ${ }^{\circ} 124414$.

[11] O. Sultana, A. Naeem, T. Mahmood, I.U. Din, T. Saeed, N. Khan, T. Ahmad, Sorption studies of chromate by iron oxide from drinking water, Z. Phys. Chem. 235 (2021) 407-425.

[12] H.P. Nogueira, S.H. Toma, A.T. Silveira, A.A.C. Carvalho, A.M. Fioroto, K. Araki, Efficient $\mathrm{Cr}(\mathrm{VI})$ removal from wastewater by activated carbon superparamagnetic composites, Microchem. J., 149 (2019) Art. N 104025.

[13] G. Stinchfield, J.F. Capitani, J. Regan, Bidentate and monodentate binding of chromium (VI) on the acid scavenger exchange resin, MP-carbonate, as a function of $\mathrm{pH}$, Water Air Soil Pollut., 231 (2020) Art. $\mathrm{N}^{\circ} 360$.

[14] G. Darmograi, B. Prelot, A. Geneste, L.-C. De Menorval, J. Zajac, Removal of three anionic orange-type dyes and $\mathrm{Cr}(\mathrm{VI})$ oxyanion from aqueous solutions onto strongly basic anion-exchange resin. the effect of single-component and competitive adsorption, Colloids Surf., A 508 (2016) 240-250.

[15] I. Chaàbna, C. Boukhalfa, Removal of chromate by Amberlite A21: kinetics and equilibrium studies, Desalin. Water Treat. 63 (2017) 152-157.

[16] Y. Yan, Q. An, Z. Xiao, W. Zheng, S. Zhai, Flexible core-shell/bead-like alginate@ PEI with exceptional adsorption capacity, recycling performance toward batch and column sorption of Cr(VI), Chem. Eng. J. 313 (2017) 475-486.

[17] M.F. Hamza, A.A.H. Abdel-Rahman, E. Guibal, Magnetic glutamine-grafted polymer for the sorption of U(VI), Nd(III) and Dy(III), J. Chem. Technol. Biotechnol. 93 (2018) 1790-1806.
[18] K.Z. Elwakeel, A.S. Al-Bogami, A.M. Elgarahy, Efficient retention of chromate from industrial wastewater onto a green magnetic polymer based on shrimp peels, J. Polym. Environ. 26 (2018) 2018-2029.

[19] S.M. Dhivya, S.M. Sathiya, G. Manivannan, M.A.J. Rajan, A comparative study on the biopolymer functionalized iron oxide nanocomposite for antimicrobial activity, Mater. Today: Proc. 3 (2016) 3866-3871.

[20] M.L. Iordache, G. Dodi, D. Hritcu, D. Draganescu, O. Chiscan, M.I. Popa, Magnetic chitosan grafted (alkyl acrylate) composite particles: synthesis, characterization and evaluation as adsorbents, Arabian J. Chem. 11 (2018) 1032-1043.

[21] I.V. Pylypchuk, D. Kolodynska, P.P. Gorbyk, Gd(III) adsorption on the DTPAfunctionalized chitosan/magnetite nanocomposites, Sep. Sci. Technol. 53 (2018) 1006-1016.

[22] G. Sun, L. Zhou, X. Tang, Z. Le, Z. Liu, G. Huang, In situ formed magnetic chitosan nanoparticles functionalized with polyethylenimine for effective U(VI) sorption, J. Radioanal. Nucl. Chem. 325 (2020) 595-604.

[23] D.W. O'Connell, B. Aszalos, C. Birkinshaw, T.F. O’Dwyer, A study of the mechanisms of divalent copper binding to a modified cellulose adsorbent, J. Appl. Polym. Sci. 116 (2010) 2496-2503.

[24] D.L. Guerra, A.C. Batista, R.R. Viana, C. Airoldi, Adsorption of rubidium on raw and MTZ- and MBI-imogolite hybrid surfaces: an evidence of the chelate effect, Desalination 275 (2011) 107-117.

[25] M.T. Maia, D.N. Sena, G.B. Calais, F.M.T. Luna, M.M. Beppu, R.S. Vieira, Effects of histidine modification of chitosan microparticles on metal ion adsorption, React. Funct. Polym., 154 (2020) Art. $\mathrm{N}^{\circ} 104694$.

[26] D. Perez-Quintanilla, A. Sanchez, I. Sierra, Preparation of hybrid organic-inorganic mesoporous silicas applied to mercury removal from aqueous media: Influence of the synthesis route on adsorption capacity and efficiency, J. Colloid Interface Sci. 472 (2016) 126-134.

[27] C. Kang, P. Wu, L. Li, L. Yu, B. Ruan, B. Gong, N. Zhu, Cr(VI) reduction and Cr(III) immobilization by resting cells of Pseudomonas aeruginosa CCTCC AB93066: spectroscopic, microscopic, and mass balance analysis, Environ. Sci. Pollut. Res. 24 (2017) 5949-5963.

[28] S. Zhang, Q. Shi, G. Korfiatis, C. Christodoulatos, H. Wang, X. Meng, Chromate removal by electrospun PVA/PEI nanofibers: adsorption, reduction, and effects of co-existing ions, Chem. Eng. J. 387 (2020), 124179.

[29] Y. Zhang, Y. Mo, T. Vincent, C. Faur, E. Guibal, Boosted Cr(VI) sorption coupled reduction from aqueous solution using quaternized algal/alginate@PEI beads, Chemosphere 281 (2021), 130844.

[30] R. Massart, Preparation of aqueous magnetic liquids in alkaline and acidic media, IEEE Trans. Magn. 17 (1981) 1247-1249.

[31] A. Fouda, S.-E.-D. Hassan, A.M. Abdo, M.S. El-Gamal, Antimicrobial, antioxidant and larvicidal activities of spherical silver nanoparticles synthesized by endophytic Streptomyces spp, Biol. Trace Elem. Res. 195 (2020) 707-724.

[32] W. Boulaiche, B. Hamdi, M. Trari, Removal of heavy metals by chitin: equilibrium, kinetic and thermodynamic studies, Appl. Water Sci, 9 (2019) Art. $\mathrm{N}^{\circ} 39$.

[33] X. Lin, G. Wei, X. Liang, J. Liu, L. Ma, J. Zhu, The competitive adsorption of chromate and sulfate on Ni-substituted magnetite surfaces: An ATR-FTIR study, Minerals, 11 (2021) Art. $\mathrm{N}^{\circ} 11010088$.

[34] R.G. White. Handbook of Industrial Infrared Analysis, Plenum Press, New York (USA), 1964, 440 pp.

[35] G. Socrates. Infrared Characteristic Group Frequencies, Chichester, John Wiley \& Sons, New York (USA), 1980, p. 153.

[36] J.-H. Kim, J.-H. Kim, V. Bokare, E.-J. Kim, Y.-Y. Chang, Y.-S. Chang, Enhanced removal of chromate from aqueous solution by sequential adsorption-reduction on mesoporous iron-iron oxide nanocomposites, J. Nanopart. Res., 14 (2012) Art. N ${ }^{\circ}$ 1010.

[37] G. Wojcik, Z. Hubicki, Sorption and reduction of chromate(VI) ions on Purolite A 830, Sep. Sci. Technol. 51 (2016) 2539-2546.

[38] R.S. Vieira, E. Meneghetti, P. Baroni, E. Guibal, V.M. Gonzalez de la Cruz, A. Caballero, E. Rodriguez-Castellon, M.M. Beppu, Chromium removal on chitosanbased sorbents - an EXAFS/XANES investigation of mechanism, Mater. Chem. Phys. 146 (2014) 412-417.

[39] V.V. Vukovic, J.M. Nedeljkovic, Surface modification of nanometer-scale silver particles by imidazole, Langmuir 9 (1993) 980-983.

[40] Y. El Aoufir, S. Zehra, H. Lgaz, A. Chaouiki, H. Serrar, S. Kaya, R. Salghi, S.K. AbdelRaheem, S. Boukhris, A. Guenbour, et al., Evaluation of inhibitive and adsorption behavior of thiazole-4-carboxylates on mild steel corrosion in $\mathrm{HCl}$, Colloids Surf., A, 606 (2020) Art. $\mathrm{N}^{\circ} 125351$.

[41] J.-P. Simonin, On the comparison of pseudo-first order and pseudo-second order rate laws in the modeling of adsorption kinetics, Chem. Eng. J. 300 (2016) $254-263$.

[42] M. Hubbe, S. Azizian, S. Douven, Implications of apparent pseudo-second-order adsorption kinetics onto cellulosic materials: a review, BioResources 14 (3) (2019) $7582-7626$.

[43] Y. Marcus, Ion Properties, Marcel Dekker Inc, New York, NY, 1997, p. 259.

[44] R.R. Escudero, M. Robitzer, F. Di Renzo, F. Quignard, Alginate aerogels as adsorbents of polar molecules from liquid hydrocarbons: Hexanol as probe molecule, Carbohydr. Polym. 75 (2009) 52-57.

[45] R.G. Pearson, Acids and bases 151 (1966) 172-177.

[46] M. Andersson Trojer, A. Movahedi, H. Blanck, M. Nydén, Imidazole and triazole coordination chemistry for antifouling coatings, J. Chem., 2013 (2013) Art. N 946739.

[47] S. Shariati, M. Khabazipour, F. Safa, Synthesis and application of amine functionalized silica mesoporous magnetite nanoparticles for removal of chromium (VI) from aqueous solutions, J. Porous Mater. 24 (2017) 129-139. 
[48] A. Nasrollahpour, S.E. Moradi, Hexavalent chromium removal from water by ionic liquid modified metal-organic frameworks adsorbent, Microporous Mesoporous Mater. 243 (2017) 47-55.

[49] I. Persson, Hydrated metal ions in aqueous solution: how regular are their structures? Pure Appl. Chem. 82 (2010) 1901-1917.

[50] K. Li, M. Li, D. Xue, Solution-phase electronegativity scale: insight into the chemical behaviors of metal ions in solution, J. Phys. Chem. A 116 (2012) 4192-4198.

[51] M.F. Hamza, Y. Wei, A. Benettayeb, X. Wang, E. Guibal, Efficient removal of uranium, cadmium and mercury from aqueous solutions using grafted hydrazidemicro-magnetite chitosan derivative, J. Mater. Sci. 55 (2020) 4193-4212.

[52] M.F. Hamza, A. Fouda, K.Z. Elwakeel, Y. Wei, E. Guibal, N.A. Hamad, Phosphorylation of guar gum/magnetite/chitosan nanocomposites for uranium (VI) sorption and antibacterial applications, Molecules, 26 (2021) Art. N 1920.

[53] R.C. Gonçalves, D.P. da Silva, R. Signini, P.L. Faleiro Naves, Inhibition of bacteria biofilms by carboxymethyl chitosan combined with silver, zinc and copper salts, Int. J. Biol. Macromol. 105 (2017) 385-392.

[54] A. Roy, O. Bulut, S. Some, A.K. Mandal, M.D. Yilmaz, Green synthesis of silver nanoparticles: biomolecule-nanoparticle organizations targeting antimicrobial activity, RSC Adv. 9 (2019) 2673-2702.

[55] S.S. Salem, A. Fouda, Green synthesis of metallic nanoparticles and thei prospective biotechnological applications: an overview, Biol. Trace Elem. Res. 199 (1) (2021) 344-370.

[56] B. Li, Y. Zhang, Y. Yang, W. Qiu, X. Wang, B. Liu, Y. Wang, G. Sun, Synthesis, characterization, and antibacterial activity of chitosan/ $/ \mathrm{TiO}_{2}$ nanocomposite against Xanthomonas oryzae pv. oryzae, Carbohydr. Polym. 152 (2016) 825-831.
[57] A. Kheiri, S.A.M. Jorf, A. Malihipour, H. Saremi, M. Nikkhah, Application of chitosan and chitosan nanoparticles for the control of Fusarium head blight of wheat (Fusarium graminearum) in vitro and greenhouse, Int. J. Biol. Macromol. 93 (2016) 1261-1272.

[58] S.-M. Taghizadeh, N. Lal, A. Ebrahiminezhad, F. Moeini, M. Seifan, Y. Ghasemi, A. Berenjian, Green and economic fabrication of zinc oxide $(\mathrm{ZnO})$ nanorods as a broadband UV blocker and antimicrobial agent, Nanomaterials, 10 (2020) Art. $\mathrm{N}^{\circ}$ 530.

[59] E.F. El-Belely, M.M.S. Farag, H.A. Said, A.S. Amin, E. Azab, A.A. Gobouri, A. Fouda, Green synthesis of zinc oxide nanoparticles (ZnO-NPs) using Arthrospira platensis (Class: Cyanophyceae) and evaluation of their biomedical activities, Nanomaterials, 11 (2021) Art. $\mathrm{N}^{\circ} 11010095$.

[60] A. Sirelkhatim, S. Mahmud, A. Seeni, N.H.M. Kaus, L.C. Ann, S.K.M. Bakhori, H. Hasan, D. Mohamad, Review on zinc oxide nanoparticles: antibacterial activity and toxicity mechanism, Nano-Micro Lett. 7 (2015) 219-242.

[61] S.-E.-D. Hassan, A. Fouda, A.A. Radwan, S.S. Salem, M.G. Barghoth, M.A. Awad, A. M. Abdo, M.S. El-Gamal, Endophytic actinomycetes Streptomyces spp mediated biosynthesis of copper oxide nanoparticles as a promising tool for biotechnological applications, J. Biol. Inorg. Chem. 24 (2019) 377-393.

[62] A. Fouda, S.E.-D. Hassan, E. Saied, M.F. Hamza, Photocatalytic degradation of real textile and tannery effluent using biosynthesized magnesium oxide nanoparticles (MgO-NPs), heavy metal adsorption, phytotoxicity, and antimicrobial activity, J. Environ. Chem. Eng., 9 (2021) Art. $\mathrm{N}^{\circ} 105346$.

[63] K.S. Siddiqi, A.u. Rahman, Tajuddin, A. Husen, Properties of zinc oxide nanoparticles and their activity against microbes, Nanoscale Res. Lett., 13 (2018) Art. $\mathrm{N}^{\circ} 141$. 